\title{
ipen
}

AUTARQUIA ASSOCIADA À UNIVERSIDADE DE SÃO PAULO

\section{DESENVOLVIMENTO DE UMA METODOLOGIA DE CALIBRAÇÃO E TESTES DE MEDIDORES DO PRODUTO KERMA-ÁREA}

NATHALIA ALMEIDA COSTA

Dissertação apresentada como parte dos requisitos para obtenção do Grau de Mestre em Ciências na Área de Tecnologia Nuclear - Aplicações

Orientadora:

Profa. Dra. Maria da Penha Albuquerque Potiens 


\title{
INSTITUTO DE PESQUISAS ENERGÉTICAS E NUCLEARES
}

Autarquia associada à Universidade de São Paulo

\section{DESENVOLVIMENTO DE UMA METODOLOGIA DE CALIBRAÇÃO E TESTES DE MEDIDORES DO PRODUTO KERMA-ÁREA}

\author{
NATHALIA ALMEIDA COSTA
}

\begin{abstract}
Dissertação apresentada como parte dos requisitos para obtenção do Grau de Mestre em Ciências na Área de Tecnologia Nuclear - Aplicações

Orientadora:

Profa. Dra. Maria da Penha Albuquerque Potiens
\end{abstract}

Versão Corrigida

Versão Original disponível no IPEN 
Dedico este trabalho à minha amada mãe Veronica 
"Mas os que esperam no Senhor, renovarão as suas forças, subirão com asas como águias, correrão e não se cansarão, caminharão $e$ não se fatigarão."

Isaias 40:31 


\section{Agradecimentos}

Em especial a Deus, por guiar todos os meus caminhos e estar sempre ao meu lado cuidando da minha vida.

À minha orientadora Dra. Maria da Penha Albuquerque Potiens pela oportunidade, dedicação, confiança, paciência e principalmente pela amizade.

Ao Prof. Lúcio Leonardo por ter sido meu guia antes do início deste trabalho.

À Radcal Corporation, pelo suporte técnico com a disponibilização do principal equipamento utilizado neste trabalho.

Ao Dr. Vitor Vivolo por estar sempre disponível na hora das dúvidas e de ajudar no laboratório.

À Dra. Linda V. E. Caldas, pela confiança no projeto e pelo empenho em fornecer a estrutura para realização da parte experimental.

À Coordenação de Aperfeiçoamento de Pessoal de Nível Superior (CAPES), pela oportunidade e pelos recursos financeiros, sem os quais não seria possível a realização desse projeto.

Ao Instituto de Pesquisas Energéticas e Nucleares (IPEN) por possibilitar o meu desenvolvimento acadêmico.

Aos amigos Elaine, Daniela, Amanda, Camila, Yklys, Fernanda, Jonas, Felipe, Maira, Talysson, Patricia, Lilian, Lucas e a todo o grupo do GMR pelo companheirismo e amizade nesses dois anos de estudos.

Ao amigo Eduardo Correa por todas as trocas de conhecimento e pela imensurável ajuda para a realização neste trabalho.

Ao amigo Marcus Oliveira por toda a colaboração e ajuda com este trabalho. 
A André Oliveira por todo o apoio e incentivo no início deste trabalho.

A toda a minha família que sempre acreditou e torceu para que eu buscasse este título, em especial ao meu tio José Helder por todo o auxílio e suporte dado nesses anos.

À equipe da Coordenadoria de Física e Higiene das Radiações e ao Hospital São Paulo pela parceria neste trabalho.

À Agência Internacional de Energia Atômica pelo suporte técnico parcial com a disponibilização de um medidor do PKA para calibração.

À clínica CEDRUL em João Pessoa, ao DEN em Recife e ao Laboratório de Física do IFBA em Salvador pela disponibilidade do uso dos equipamentos e pela atenção dada.

A todos os outros não mencionados que, direta ou indiretamente, contribuíram para a conclusão desse trabalho. 


\title{
DESENVOLVIMENTO DE UMA METODOLOGIA DE CALIBRAÇÃO E TESTES DE MEDIDORES DO PRODUTO KERMA-ÁREA
}

\author{
Nathalia Almeida Costa
}

\begin{abstract}
RESUMO
A grandeza produto kerma-área (PKA) é importante para estabelecer níveis de referência em exames de radiologia diagnóstica. Essa grandeza pode ser obtida por meio de medidores do PKA. O uso desses medidores é fundamental para avaliar a dose de radiação em procedimentos radiológicos, além de ser um bom indicador para que os limites de dose na pele do paciente não sejam excedidos. Algumas vezes, esses medidores vêm acoplados a equipamentos de radiação $X$, o que dificulta sua calibração. Neste trabalho foi desenvolvida uma metodologia de calibração de medidores do PKA. O instrumento utilizado para este fim foi o Patient Dose Calibrator (PDC). Ele foi desenvolvido para ser utilizado como referência na verificação da calibração de medidores do PKA e kerma no ar usados na dosimetria de pacientes e para verificação da consistência e do comportamento de sistemas de controle de exposição automáticos. Por se tratar de um equipamento novo, que, no Brasil, ainda não é utilizado como equipamento de referência para calibração, foi realizado, também o controle de qualidade deste equipamento, com testes de caracterização, a calibração e a avaliação da dependência energética. Após os testes, ficou provado que o PDC pode ser utilizado como instrumento de referência para a calibração a ser realizada in situ, de forma que as características de cada equipamento de radiação $X$ onde os medidores do PKA são utilizados sejam consideradas. A calibração foi, então, realizada com medidores do PKA portáteis e em um equipamento de radiologia intervencionista que possui um medidor do PKA acoplado. Os resultados foram bons e ficou provada a necessidade de calibração desses medidores e a importância da calibração in situ com um medidor de referência.
\end{abstract}




\title{
DEVELOPMENT OF A CALIBRATION METHODOLOGY AND TESTS OF KERMA AREA PRODUCT METERS
}

\author{
Nathalia Almeida Costa
}

\begin{abstract}
The quantity kerma area product (PKA) is important to establish reference levels in diagnostic radiology exams. This quantity can be obtained using a PKA meter. The use of such meters is essential to evaluate the radiation dose in radiological procedures and is a good indicator to make sure that the dose limit to the patient's skin doesn't exceed. Sometimes, these meters come fixed to $X$ radiation equipment, which makes its calibration difficult. In this work, it was developed a methodology for calibration of PKA meters. The instrument used for this purpose was the Patient Dose Calibrator (PDC). It was developed to be used as a reference to check the calibration of PKA and air kerma meters that are used for dosimetry in patients and to verify the consistency and behavior of systems of automatic exposure control. Because it is a new equipment, which, in Brazil, is not yet used as reference equipment for calibration, it was also performed the quality control of this equipment with characterization tests, the calibration and an evaluation of the energy dependence. After the tests, it was proved that the PDC can be used as a reference instrument and that the calibration must be performed in situ, so that the characteristics of each X-ray equipment, where the PKA meters are used, are considered. The calibration was then performed with portable PKA meters and in an interventional radiology equipment that has a PKA meter fixed. The results were good and it was proved the need for calibration of these meters and the importance of in situ calibration with a reference meter.
\end{abstract}




\section{SUMÁRIO}

Dedicatória..................................................................................... ii

Agradecimentos.......................................................................... iv

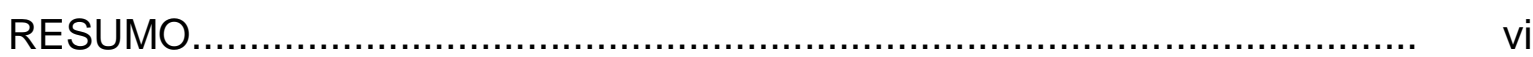

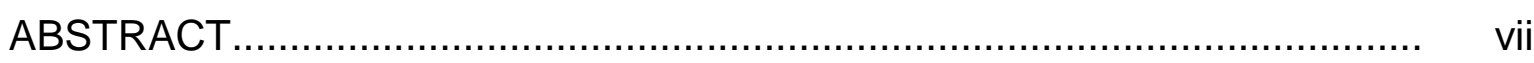

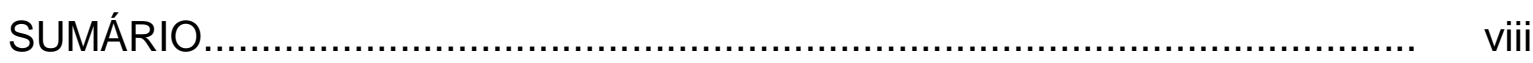

LISTA DE TABELAS. ................................................................ xi

LISTA DE FIGURAS............................................................................ xii

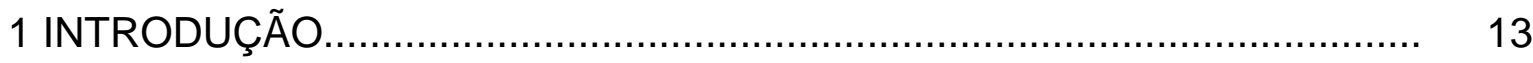

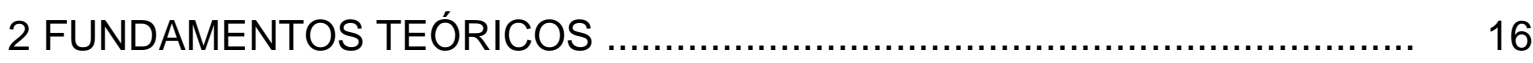

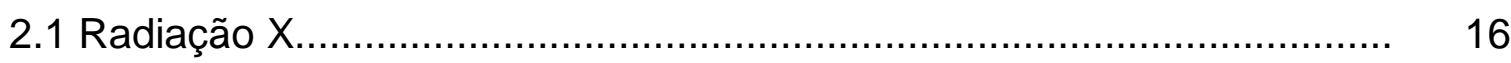

2.1.1 Produção da radiação X.............................................................. 18

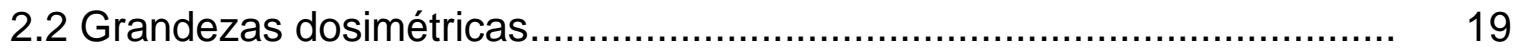

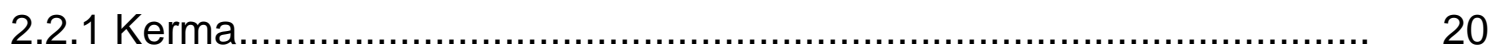

2.2.2 Taxa de kerma.................................................................. 20

2.2.3 Kerma no ar incidente................................................................ 20

2.2.4 Kerma no ar na superfície de entrada............................................. 21

2.2.5 Produto kerma-área...................................................................... 21

2.3 Câmaras de lonização..................................................................... 21

2.3.1 Câmaras de ar livre................................................................ 22

2.3.2 Câmaras cilíndricas.................................................................... 23

2.3.3 Câmaras de placas paralelas........................................................ 24

2.3.4 Câmaras cavitárias....................................................................... 25

2.3.5 Câmaras de extrapolação.............................................................. 26

2.3.6 Câmaras de Transmissão................................................................. 27

2.3.7 Medidor dose area product (DAP) .................................................. 28

2.3.8 Patient dose calibrator............................................................. 29

2.4 Calibração de Instrumentos.......................................................... 31

2.4.1 Instalação para a calibração de câmaras de PKA.............................. 33

2.4.2 Calibração de medidores do PKA em termos do produto kerma-área para radiação transmitida e incidente......................................... 35

2.4.3 Calibração in situ.................................................................. 35

2.4.3.1 Calibração in situ com um dosímetro diagnóstico.......................... 37 
2.4.3.2 Calibração in situ com um medidor do PKA de referência.

2.4.4 Calibração método tandem.......................................................... 40

3 MATERIAIS E MÉTODOS.................................................................... 42

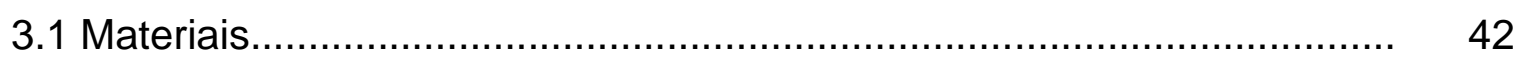

3.1.1 Sistemas de Dosimetria................................................................. 42

3.1.2 Sistemas de Radiação X............................................................ 44

3.1.3 Outros equipamentos................................................................... 46

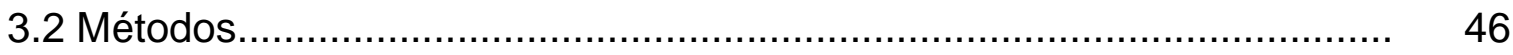

3.2.1 Testes realizados no IPEN............................................................. 46

3.2.1.1 Medições nas qualidades implantadas no sistema de radiação X. $\quad 46$

3.2.1.2 Avaliação de desempenho do PDC de acordo com as normas IEC 61674 e IEC 60580................................................................. 47

3.2.1.3 Calibração do PDC segundo a norma TRS 457 ........................... 48

3.2.1.4 Avaliação da dependência energética......................................... 50

3.2.1.5 Avaliação de desempenho para as qualidades de mamografia..... $\quad 50$

3.3 Calibração de medidores do PKA utilizando o PDC como referência..... 51

3.3.1 Testes realizados na UNIFESP.................................................. 52

3.3.1.1 Calibração de um medidor do PKA acoplado a um sistema intervencionista.............................................................................. 52

3.3.2 Testes realizados no CEDRUL.................................................... 54

3.3.3 Testes realizados no DEN............................................................. 54

3.3.3.1 Medições nas qualidades implantadas no sistema de radiação X. $\quad 54$

3.3.3.2 Calibração do DAP............................................................... 55

3.3.4 Testes realizados no IFBA............................................................ 56

3.3.5 Análise das Incertezas................................................................... 5

4 RESULTADOS E DISCUSSÕES.............................................................. 59

4.1 Avaliação de desempenho do PDC de acordo com as normas IEC

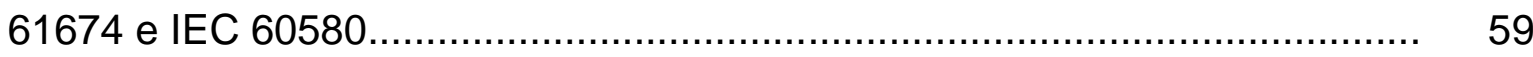

4.2 Calibração do PDC segundo a norma TRS 457 ..................................... 60

4.3 Avaliação da dependência energética.................................................... 61

4.4 Uso do PDC em equipamentos de mamografia....................................... 62

4.5 Calibração de medidores do PKA utilizando o PDC como referência...... 63 
4.5.1 Calibração de um medidor do PKA acoplado a um sistema

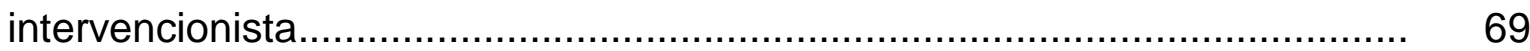

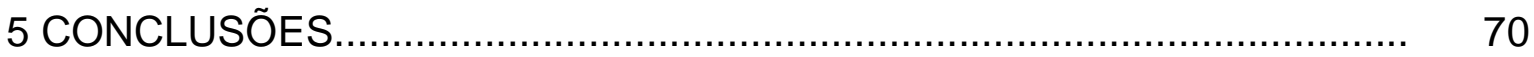

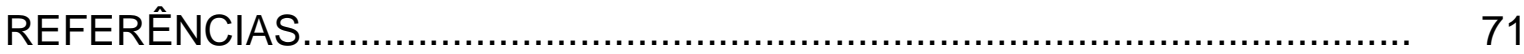




\section{LISTA DE TABELAS}

TABELA 1. Qualidades de radiação estabelecidas no LCI-IPEN para 44 radiodiagnóstico

TABELA 2. Fator de Correção para a câmara de ionização padrão RC6 no 48 sistema de radiação $X$ do $L C l$ do IPEN.

TABELA 3. Valores de camada semirredutora do sistema de radiação $X$ do 49 LCI do IPEN.

TABELA 4. Condições de Irradiação nos locais onde o método de calibração 50 foi aplicado

TABELA 5 Características do PDC e seus limites

TABELA 6. Coeficientes de Calibração e fatores de correção do PDC. 58

TABELA 7. Valores obtidos para WMV 60

TABELA 8. Valores obtidos para WMH 60

TABELA 9. Valores de PKA e Kerma no ar obtidos na UNIFESP - São Paulo 61

TABELA 10. Valores de Coeficiente de Calibração $\left(N_{K}\right)$ obtidos para o DAP 62 da UNIFESP.

TABELA 11. Valores de PKA e Kerma no ar obtidos no CEDRUL - João 63 Pessoa

TABELA 12. Valores de Coeficiente de Calibração $\left(N_{K}\right)$ obtidos para o DAP 64 do IFBA utilizado no CEDRUL

TABELA 13. Valores de PKA e Kerma no ar obtidos no DEN - Recife

TABELA 14. Valores de Coeficiente de Calibração $\left(N_{K}\right)$ obtidos para o DAP 65 do DEN

TABELA 15. Valores de PKA e Kerma no ar obtidos no IFBA - Salvador

TABELA 16. Valores de Coeficiente de Calibração $\left(N_{K}\right)$ obtidos para o DAP 67 do IFBA

TABELA 17. Resultados encontrados para calibração in situ em um 67 equipamento de cardiologia intervencionista. 


\section{LISTA DE FIGURAS}

FIGURA 1. Arranjo de uma câmara de ar livre 22

FIGURA 2. Arranjo de uma câmara cilíndrica 23

FIGURA 3. Arranjo de uma câmara de ionização de placas paralelas 25

FIGURA 4. Arranjo de uma câmara cavitária 26

FIGURA 5. Arranjo de uma câmara de extrapolação 27

FIGURA 6. Arranjo de uma câmara de transmissão 28

FIGURA 7. Arranjo de um medidor DAP 29

FIGURA 8. Em 1 o Patient Dose Calibrator e em 2 o seu suporte 31

FIGURA 9. Arranjo para calibração de medidores do PKA 34

FIGURA 10. Arranjo para calibração de medidores do PKA in situ 38

FIGURA 11. Câmara de lonização RC6 41

FIGURA 12. Câmara de lonização 20X6-3 41

FIGURA 13. Medidor do PKA Diamentor E2 da Unifesp 42

FIGURA 14. Medidor do PKA KermaX® plus TinO (Two in One) 120205 do IFBA

FIGURA 15. Medidor do PKA Diamentor E2 da UFPE 43

FIGURA 16. Sistema de Radiação X Pantak/Seifert do IPEN 44

FIGURA 17. Medições nas qualidades de radiação implantadas no LCl 46

FIGURA 18. Posicionamento da câmara RC6 para calibração do PDC. 48

FIGURA 19. llustração do arranjo de calibração do DAP com o PDC 51

FIGURA 20. Ilustração do arranjo de calibração de um DAP que é acoplado a um sistema intervencionista

FIGURA 21. Calibração do DAP do DEN. DAP posicionado na saída do feixe de radiação $X$ e o $P D C$ posicionado abaixo, no suporte.

FIGURA 22. Campo de $10 \mathrm{~cm} \times 10 \mathrm{~cm}$ radiografado para confirmação de tamanho no DEN

FIGURA 23. Campo de $10 \mathrm{~cm} \times 10 \mathrm{~cm}$ radiografado para confirmação de tamanho no IFBA

FIGURA 24. Dependência energética do PDC para as qualidades de radiodiagnóstico implantadas no $\mathrm{LCl}$ 


\section{INTRODUÇÃO}

O uso de medidores do produto kerma-área (PKA) é fundamental para avaliar a dose de radiação em procedimentos radiológicos. Seu uso é retratado principalmente para a determinação de níveis de referência de diagnóstico para exames de radiologia convencional e é um bom indicador para que os limites de dose de entrada na pele do paciente para efeitos determinísticos não sejam excedidos em procedimentos intervencionistas ${ }^{1,2}$. A utilização principal de medidores do PKA, além de equipamentos de radiação $X$ diagnósticos, é em equipamentos de procedimentos intervencionistas (equipamentos fluoroscópicos e serviços de hemodinâmica) e em tomógrafos de feixe cônico $^{3,4}$. Nesses equipamentos, o medidor do PKA é acoplado de modo que não pode ser retirado para calibração em laboratório.

O PKA é usualmente medido com uma câmara de ionização de transmissão de placas paralelas. O sinal deste tipo de câmara é proporcional à integral da superfície sobre a área sensível da câmara. A partir do conceito do PKA, fica pressuposto que a área de integração da definição e a área sensível da câmara nas medições são grandes o suficiente para cobrir todo o feixe de radiação, incluindo as áreas de penumbra. Em feixes ideais, o valor do PKA é independente da distância do ponto focal do tubo de radiação $X$. Na prática, radiação extrafocal e espalhada e atenuação no ar afetam o PKA, resultando em dependência no plano e na área de integração $0^{5}$.

Medidores do PKA são geralmente montados na saída do feixe de radiação, após o colimador do feixe, e envolve todo o campo de radiação. Teoricamente, desconsiderando o espalhamento e a radiação extrafocal, o PKA é o mesmo ao longo do eixo central de raios $X$. Consequentemente, o PKA medido por um medidor do PKA posicionado na saída do feixe de radiação é o mesmo que atinge a pele do paciente. Este fato torna vantajoso o uso de um medidor do PKA para dosimetria do paciente, uma vez que as leituras realizadas pelo medidor do PKA podem ser relacionadas com a energia transmitida ao paciente, independente da área de radiação, da distância ponto focal-pele, da direção do feixe de raios $X$, etc.

Dependendo do seu uso e da calibração, medidores do PKA medem a radiação incidente, que é a radiação que atinge a câmara, ou a radiação transmitida, que é a radiação que emerge da câmara. A radiação transmitida inclui a atenuação 
da radiação pela câmara. Medidores do PKA instalados na saída do feixe de radiação medem a radiação transmitida, enquanto que medidores do PKA para dosimetria de feixes de raios $X$ medem a radiação incidente ${ }^{6}$.

Para alcançar acurácia adequada nas medições com este tipo de medidor é necessário que uma calibração apropriada seja realizada. Existem três formas de calibração para medidores do PKA: em laboratório, com uma câmara de ionização de referência ou com um medidor do PKA de referência. Um método alternativo seria baseado em medidas do kerma no ar no plano de referência e determinação do PKA calculando a área no mesmo plano.

Medidores do PKA portáteis podem ser calibrados em laboratório, mas os efeitos da radiação extrafocal e espalhada podem ser mensurados somente no equipamento de radiação $X$ no qual o medidor do PKA é utilizado para medições com pacientes. O método de calibração com um medidor do PKA de referência é considerado efetivo, pois a calibração é realizada no próprio equipamento de raios $X$ onde o medidor do PKA é utilizado, mantendo-se a geometria do feixe como usada com pacientes e considerando características específicas de radiação extrafocal e espalhada do equipamento ${ }^{5}$. Outro importante fator para a calibração com um medidor do PKA de referência, ou calibração in situ, é o controle de distribuição homogêneo de kerma no ar no feixe causado pelo efeito anódico e também pela radiação extrafocal ${ }^{1}$. O arranjo da calibração in situ pode ser simulado na calibração com pequenas instrumentações adicionais e o campo do medidor do PKA pode ser usado na posição normal. A calibração pode ser também realizada para câmaras de PKA fixas e sistemas que não podem ser separados do equipamento de raios $X^{5}$.

Num panorama internacional, a norma IEC $60580^{7}$ estabelece os padrões de desempenho e comportamento para esses medidores. Porém, essa norma não descreve um procedimento de calibração. Já o código de prática TRS $457^{1}$ descreve o procedimento de calibração para medidores do PKA em laboratório, com a utilização de uma câmara de ionização de referência e com um medidor do PKA de referência.

No Brasil, não existe uma norma ou recomendação específica para a utilização deste tipo de instrumento. A portaria $453^{8}$ da Anvisa, que estabelece diretrizes de proteção radiológica para serviços de radiodiagnóstico, institui que o controle de qualidade, previsto no programa de garantia de qualidade, deve incluir 
um conjunto mínimo de testes de constância, do qual fazem parte os valores representativos de taxa de dose dada ao paciente em fluoroscopia e do tempo de exame, ou do produto dose-área ou PKA, com uma frequência bianual. Porém, não existe um procedimento padrão estabelecido de calibração deste tipo de medidor.

Dada a dificuldade de calibração de medidores do PKA fixos, estudos realizados na Finlândia mostraram que existe a possibilidade de calibração de medidores do PKA in situ. Estes estudos foram realizados utilizando o Patient Dose Calibrator (PDC) como equipamento de referência para calibração de medidores do PKA, num método conhecido como tandem (em conjunto), o que torna possível a calibração in situ, especialmente para equipamentos de fluoroscopia que possuem um medidor do PKA acoplado no equipamento, sem que haja a possibilidade de remoção para que seja calibrado em laboratório ${ }^{5,9}$. O PDC é um novo equipamento da marca Radcal, que tem a função de medir o PKA e o kerma no ar, além da taxa de PKA e da taxa de kerma no ar e que deve ser utilizado como medidor do PKA de referência para a calibração de medidores do PKA.

Portanto, o objetivo principal deste estudo é o desenvolvimento e a aplicação de uma metodologia de calibração e testes de medidores do PKA com a utilização de um PDC como referência. O controle de qualidade e a caracterização do PDC foram realizados a fim de assegurar que ele pudesse ser utilizado para calibração de medidores do PKA. 


\section{FUNDAMENTOS TEÓRICOS}

\subsection{Radiação X}

A radiação $X$ foi descoberta pelo físico alemão Wilhelm Conrad Roentgen em 1895. Roentgen verificou que durante o tempo de duração da descarga elétrica na ampola era produzida uma luminescência sobre a tela de material fosforescente disponível em seu laboratório. Repetindo as descargas, ele verificou também que mesmo que fossem colocados obstáculos entre a ampola e a tela fosforescente, a luminescência continuava aparecendo. Intrigado com o fenômeno, ele realizou estudos para entender a natureza da radiação emitida pela ampola e também para caracterizar seu comportamento e a capacidade de penetração em diferentes tipos de obstáculos. Além de sensibilizar telas fosforescentes, a referida radiação também possuía a capacidade de enegrecer filmes fotográficos. Esses estudos levaram ao desenvolvimento de experimentos que permitiram o registro em filme fotográfico de estruturas internas de materiais sólidos e opacos. Essa capacidade foi logo testada por Roentgen, que viu os ossos da mão de sua esposa, o que hoje é considerada a primeira radiografia.

O uso médico da radiação $X$ disseminou-se pelo mundo, apesar de haver um grande desconhecimento de eventuais efeitos colaterais que pudessem advir de sua utilização. A absoluta falta de proteção, tantos de pacientes quanto de profissionais, com o tempo levou ao aparecimento de malefícios causados pela radiação. Isso fez com que seu uso fosse mais restrito e cercado de cuidados especiais como forma de proteger aqueles que dela faziam uso.

A radiação $X$ é produzida artificialmente na ampola por meio da aceleração de elétrons contra um material metálico de alto número atômico. Resulta desse choque a emissão de uma radiação eletromagnética, caracterizada por uma frequência muito alta, pequeno comprimento de onda e alto poder de penetração.

$A$ radiação $X$ tem natureza eletromagnética e se propaga através de qualquer material, ou mesmo no vácuo. Sua velocidade é igual à velocidade da luz, pois a luz também é uma onda eletromagnética. Essa radiação é produzida de várias maneiras, mas todas estão envolvidas com a emissão de um excesso de energia que os elétrons carregam e que pode ser emitido quando ocorre o bombardeamento de um material metálico por um feixe de elétrons. Na colisão, os elétrons emitem 
energia na forma de fótons, com as mais diversas energias (frequências). Algumas delas estão situadas na faixa conhecida como radiação $X$, enquanto outras são frequências térmicas (calor).

A radiação eletromagnética é quantizada, ou seja, só existe em quantidades discretas ou valores definidos. Os fótons da radiação $X$ possuem um comportamento de partículas, algumas vezes, e de ondas, outras vezes, mas não possuem massa dinâmica.

A radiação $X$ possui características ionizantes, ou seja, possui a capacidade de ionizar o meio onde se propaga, arrancando elétrons dos átomos com os quais interage. Essa característica é extremamente importante, pois quando ocorre a interação da radiação com os tecidos em nível atômico, a ionização dos átomos altera a forma como eles se ligam a outros átomos vizinhos, provocando uma mudança nas características dos tecidos irradiados. A característica ionizante da radiação $X$ é muito utilizada em equipamentos de medição de radiação. Ao ionizar um gás pelo qual passa, a radiação deixa íons que podem ser quantificados, determinando assim a quantidade de radiação que o atravessou.

$O$ fenômeno de produção da radiação $X$ ocorre quando uma quantidade grande de elétrons com muita energia é lançada contra um conjunto de átomos. Esses elétrons colidem com o átomo-alvo e podem sofrer três tipos de interação:

a) desviar a trajetória;

b) chocar-se com o núcleo do átomo;

c) chocar-se com um elétron do átomo.

Em qualquer uma dessas situações, o elétron terá que converter a energia cinética que possui em um fóton para poder emitir energia, que poderá então ter qualquer valor, entre uma energia mínima, praticamente zero, até toda a energia cinética de que o elétron dispuser.

Em resumo, uma radiação é considerada ionizante se for capaz de arrancar um elétron de um átomo ou de uma molécula, ao qual ele está ligado por força elétrica. Quando um elétron é ejetado de um átomo, forma-se o par íon positivo - íon negativo (elétron) ${ }^{10}$. 


\subsubsection{Produção da radiação $X$}

Em um tubo de radiação $X$, a maioria dos elétrons incidentes sobre 0 alvo perde energia cinética de modo gradual nas inúmeras colisões, convertendo-as em calor. Esse é o motivo pelo qual o alvo deve ser feito de material de alto ponto de fusão, como o tungstênio (W) ou o molibdênio (Mo). Em geral, é ainda necessário resfriar o tubo por meio de técnicas de refrigeração, que incluem materiais com grandes massas térmicas, cujo calor é extraído com circuito fechado de óleo e água corrente e/ou circulante.

Os processos fundamentais envolvidos na produção de radiação $X$ são dois. Em um deles, os raios $X$ produzidos, chamados de raios $X$ de freamento, apresentam um espectro contínuo de energias, e no outro, chamados raios $X$ característicos, um espectro de linhas com energias bem definidas.

$A$ radiação de freamento é definida quando um fóton de raios $X$ é criado quando um elétron sofre uma desaceleração brusca devido à atração causada pelo campo coulombiano do núcleo. Podem ter qualquer energia, que depende do grau de aproximação do elétron do núcleo e da energia cinética do elétron.

Já a radiação característica possui um espectro de energia discreto. Da mesma forma que um fóton de luz é emitido quando um elétron da camada mais externa de um átomo decai de um nível de energia mais alto para outro de energia mais baixo, um fóton de energia na faixa de raios $X$ é emitido quando as transições do elétron envolvem camadas mais internas do átomo. No primeiro caso, da emissão de um fóton de luz, a energia envolvida é da ordem de poucos $\mathrm{eV}$, e no segundo, da emissão de um fóton de raios $X$, de muitos keV.

Quando um elétron incidente no alvo remove um elétron da camada $K$, cria-se um buraco em seu lugar, que é imediatamente preenchido pela transição de um elétron da camada mais externa ${ }^{11}$. 


\subsection{Grandezas Dosimétricas}

$\mathrm{Na}$ área de radiodiagnóstico, a grandeza fundamental na qual os padrões nacionais são calibrados é o kerma no ar. A partir do kerma no ar podem-se determinar todas as demais grandezas de uso prático.

As medições de radiação, nesta área, são fundamentais para os programas de controle de qualidade dos equipamentos de raios $\mathrm{X}$ e para medir ou estimar doses a que os pacientes estão submetidos, ou seja, na dosimetria do paciente. Para o controle de qualidade, a grandeza kerma no ar é suficiente, tanto na caracterização e controle da fonte (campo de radiação incidente no paciente) quanto para a avaliação do desempenho do sistema de captação e registro da imagem (campo de radiação pós-paciente).

A dosimetria do paciente é um pouco mais complexa devido a diversidade de técnicas para obtenção da imagem e as diferentes intensidades, durações e energias dos campos utilizados. Como agravante, tem aparecido de uma profusão de grandezas para cada técnica.

Enquanto que em algumas situações a grandeza dosimétrica de interesse pode ser medida diretamente, em outras, a medição direta não é possível, como, por exemplo, na medição de dose em um órgão ou tecido interno. Neste caso obtém-se a dose indiretamente através da aplicação de um coeficiente de conversão tabelado, a partir de uma grandeza medida diretamente.

Até o momento, as diferentes grandezas propostas partem da definição de grandezas dosimétricas básicas (kerma no ar, dose absorvida ou exposição), mas levam em conta as condições em que as medições são realizadas (livre no ar, no paciente ou no simulador) e o meio em que são expressos os valores da grandeza (no ar, na pele ou no tecido mole).

Fica evidente a necessidade de recomendações de diferentes grandezas para as diferentes técnicas de investigações por radiodiagnóstico: radiografia, fluoroscopia, mamografia e tomografia computadorizada. Organismos internacionais como a International Atomic Energy Agency (IAEA) e International Commission on Radiation Units and Measurements (ICRU), nestes últimos anos, têm se esforçado para estabelecer um sistema harmonizado de grandezas, símbolos e unidades, a fim de preencher esta lacuna numa das áreas mais antigas de aplicação de raios $\mathrm{X}$. 
A seguir serão apresentadas as definições da grandeza dosimétrica kerma de acordo com a IAEA no Technical Reports Series número $457^{1}$ que fornece recomendações sobre a utilização de equipamentos de medida e da aplicação de procedimentos de controle de qualidade nas clínicas e hospitais que possuem serviços de radiodiagnóstico. O principal objetivo do TRS é ajudar a alcançar e manter um alto nível de qualidade metrológica em dosimetria para o aperfeiçoamento e implementação de padrões rastreáveis e garantir o controle da dose em radiodiagnóstico em todo o mundo.

\subsubsection{Kerma}

Kerma é o quociente de $\mathrm{d} E \operatorname{tr}$ por $\mathrm{d} m$, onde $\mathrm{d} E$ tr é a soma das energias cinéticas iniciais de todas as partículas carregadas liberadas por partículas sem carga numa massa d $m$ do material. Assim:

$$
\mathrm{K}=\frac{\mathrm{dEtr}}{\mathrm{dm}}
$$

Unidade: $\mathrm{J} / \mathrm{Kg}$. O nome dado para essa unidade de kerma é gray (Gy).

\subsubsection{Taxa de Kerma}

A taxa de kerma, $K$, é dada pelo quociente de $\mathrm{d} K$ por $\mathrm{d} t$, onde $\mathrm{d} K$ é o incremento do kerma em um intervalo de tempo. Assim:

$$
\dot{K}=\frac{\mathrm{dK}}{\mathrm{dt}}
$$

Unidade: $\mathrm{J}_{\mathrm{kg}} \mathrm{kg}^{-1} \cdot \mathrm{s}^{-1}$. Se o nome gray for utilizado, a unidade de taxa de kerma é gray por segundo (Gy/s).

\subsubsection{Kerma no ar incidente}

O kerma no ar incidente, $\mathrm{K}_{\mathrm{i}}$, é o kerma no ar de um feixe de radiação incidente medido no eixo central do feixe na posição do paciente, ou seja, no plano de entrada da pele. Somente a radiação incidente no paciente ou no simulador é incluída e nenhuma radiação retroespalhada. Unidade: J/kg (Gy) 


\subsubsection{Kerma no ar na superfície de entrada}

$\mathrm{O}$ kerma no ar na superfície de entrada, $\mathrm{K}_{\mathrm{e}}$, é o kerma no ar medido no eixo central do feixe na posição do paciente ou no simulador. A radiação incidente no paciente ou simulador e a radiação retroespalhada são incluídas.

O kerma no ar na superfície de entrada está relacionado com o kerma no ar incidente pelo fator de retroespalhamento, $B$, sendo:

$$
\mathrm{K}_{\mathrm{e}=} \mathrm{K}_{\mathrm{i} . \mathrm{B}}
$$

Unidade: $\mathrm{J} / \mathrm{kg}$ (Gy)

\subsubsection{Produto kerma-área}

O produto kerma-área, PKA, é a integral do kerma no ar livre no ar sobre a área $\mathrm{A}$ do feixe de raios $\mathrm{X}$ em um plano perpendicular ao seu eixo. Assim:

$$
\mathrm{PKA}=\int_{\mathrm{A}} \mathrm{K}(x, y) \mathrm{d} x \mathrm{~d} y
$$

Unidade: $\mathrm{J}_{\mathrm{kg}} \mathrm{g}^{-1} \cdot \mathrm{m}^{2}$. Se o nome gray for utilizado, a unidade do produto kermaárea é Gy.m².

O produto kerma-área possui uma propriedade importante de ser aproximadamente invariável com a distância do foco do tubo de raios $\mathrm{X}$ (quando interações no ar e radiação extrafocal podem ser negligenciadas), considerando que o plano de cálculos e medida não está tão próximo ao paciente ou simulador onde há uma significativa contribuição da radiação retroespalhada.

\subsection{Câmaras de lonização}

As câmaras de ionização são os tipos de dosímetros mais usados para medições precisas de radiação. Podem ser utilizados para a deteç̧ão e medição das radiações $X$, alfa, beta, gama e fragmentos de fissão. Estão disponíveis comercialmente em uma variedade de modelos para diferentes aplicações.

Câmaras de ionização são abertas e utilizam o ar do próprio ambiente como o gás de seu volume sensível. Como a resposta da câmara depende da densidade do 
gás de preenchimento, a leitura obtida pela câmara aberta deve ser corrigida. Essa correção é feita em relação às condições ambientais de referência.

Os tipos de câmaras de ionização existentes estão descritos a seguir ${ }^{12}$.

\subsubsection{Câmaras de Ar Livre}

As câmaras de ar livre não possuem uma janela de entrada e, assim, são muito grandes para que o equilíbrio de partículas carregadas seja alcançado. Por esse motivo, as câmaras de ar livre são utilizadas somente para radiação $X$ com tensões de até $300 \mathrm{kV}$. São detectores absolutos, ou seja, não necessitam de coeficiente de calibração, pois medem grandezas físicas básicas (carga e massa) diretamente e, assim, a exposição pode ser determinada. A utilização de uma câmara de ar livre possibilita um conhecimento exato da massa de ar na qual os elétrons estão sendo liberados pela radiação e a determinação absoluta da grandeza exposição. $O$ volume que contém a massa de ar é definido pela área efetiva do diafragma e pelo campo elétrico aplicado a câmara. A sua utilização permite a coleta quase que integral do número de íons produzidos por estes elétrons, através da medida da corrente de ionização ${ }^{12}$. A FIG. 1 mostra o esquema interno de uma câmara de ionização de ar livre.

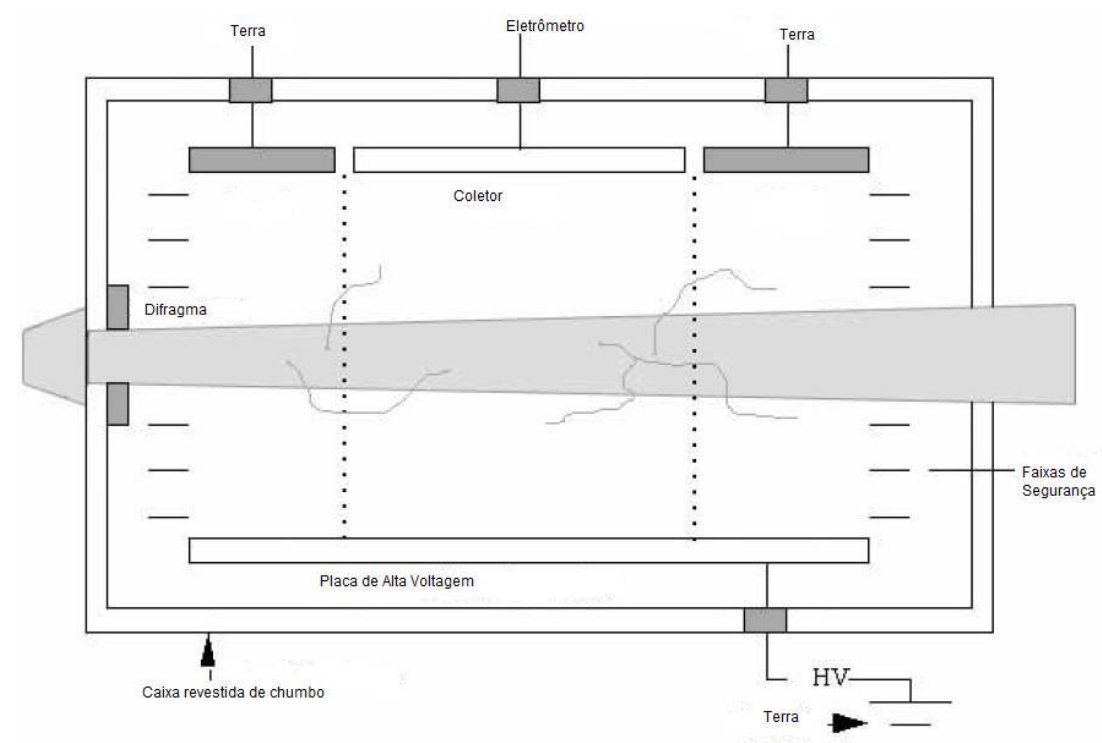

Figura 1. Esquema de uma câmara de ar livre ${ }^{1}$ 


\subsubsection{Câmaras Cilíndricas}

As câmaras de ionização cilíndricas devem ser utilizadas para calibração de feixes de raios $X$ de radioterapia com energia média acima de $80 \mathrm{kV}$ e uma camada semirredutora de $2 \mathrm{~mm}$ de alumínio, radiação gama, feixes de fóton de alta energia, feixes de elétrons com energia acima de $10 \mathrm{MeV}$ aproximadamente, etc. Este tipo de câmara é adequada para medições dessas qualidades de radiação e é resistente e simples para uso em medições com fantomas de água. O volume da cavidade da câmara deve ser entre $0,1 \mathrm{~cm}^{3}$ e $1 \mathrm{~cm}^{3}$. Esta faixa de tamanho é uma combinação entre a necessidade de sensibilidade suficiente e a habilidade de medição de dose num ponto. Estas exigências são alcançadas em câmaras cilíndricas com uma cavidade de ar com diâmetro interno não maior do que $7 \mathrm{~mm}$ e um comprimento interno não maior do que $25 \mathrm{~mm}$. Em uso, a câmara deve ser alinhada de forma que a fluência da radiação seja aproximadamente uniforme através da seção transversal da cavidade da câmara. O comprimento da cavidade, portanto, define um limite menor no tamanho do campo no qual as medições devem ser feitas.

É necessário definir a função de uso da câmara cilíndrica, se será usada como instrumento de referência (calibrada em laboratório de padrão secundário e usada para calibração do feixe) ou como instrumento de campo (calibração cruzada contra uma câmara de referência e, normalmente, utilizada para medições rotineiras). Câmaras construídas com parede de grafite geralmente possuem maior estabilidade e maior uniformidade de resposta do que câmaras com paredes plásticas. Entretanto, as paredes plásticas são mais resistentes e, portanto, mais adaptáveis para medições de rotina ${ }^{13}$. A FIG. 2 mostra o esquema interno de uma câmara de ionização cilíndrica.

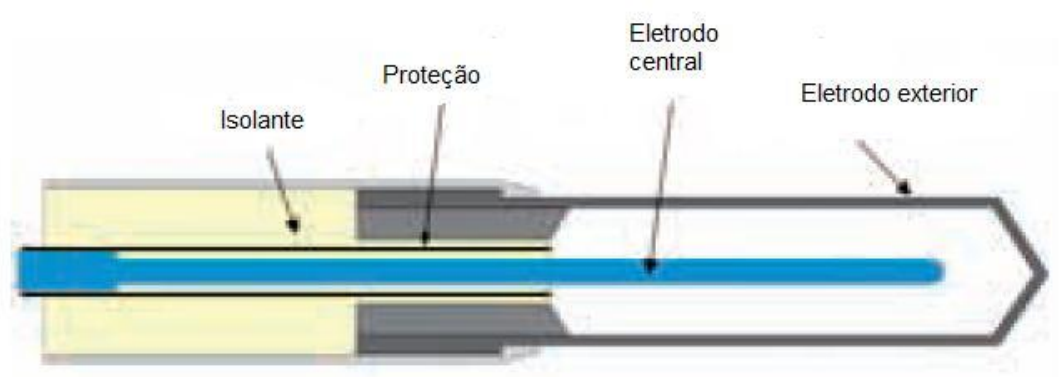

Figura 2. Esquema de uma câmara cilíndrica ${ }^{12}$ 


\subsubsection{Câmaras de Placas Paralelas}

A dosimetria da radiação $X$ gerada a valores baixos de potencial (12 a $70 \mathrm{kV}$ ) apresenta dificuldades especiais, devido a absorção considerável desta radiação mesmo quando se utilizam paredes finas de material equivalente ao ar no detector de radiação.

Geralmente, para estes casos, são utilizadas câmaras de ionização de placas paralelas, também chamadas de superficiais por serem utilizadas em feixes de radiação $X$ de energias baixas para fins de radioterapia superficial, onde se pretende determinar a dose que será ministrada ao paciente.

As próprias paredes das câmaras de placas paralelas constituem os eletrodos, distanciados um do outro de no máximo $5 \mathrm{~mm}$. Desta forma, a probabilidade dos íons positivos e negativos, formados ao longo das trajetórias dos elétrons secundários, liberados na cavidade de ar existente entre os eletrodos da câmara, sofrerem recombinações antes de atingirem o eletrodo coletor, será muito pequena. Isto garante que todos os íons produzidos dentro do volume sensível da câmara serão coletados, isto é, tem-se a saturação da corrente de ionização, mesmo em taxas de exposição altas ${ }^{1}$.

Estas câmaras são utilizadas tanto como padrões secundários como para medidas rotineiras da exposição produzida por campos de raios $X$ de energias baixas.

As câmaras de ionização de placas paralelas são caracterizadas pelos seguintes detalhes de construção:

a) O volume de ar é um cilindro circular com formato de disco, um lado plano na qual constitui a janela de entrada. A superfície interna da janela de entrada conduz eletricidade e forma o eletrodo externo. O volume sensível é a fração do volume de ar total através do qual linhas de campo passam entre o interior e 0 exterior.

b) Os eletrodos internos e externos são montados num bloco de suporte onde o cabo conector é fixado. O cabo e/ou conexão elétrica, geralmente existe no interior, paralelamente à janela de entrada.

c) O volume sensível está geralmente entre $0,05 \mathrm{~cm}^{3}$ e $0,5 \mathrm{~cm}^{3}$.

d) O potencial de polarização é aplicado ao eletrodo externo e o sinal de carga é coletado pelo eletrodo interno. 
e) Existe ainda um anel de guarda entre os outros dois que não é conectado eletricamente a nenhum deles, mas que é projetado para ser mantido no mesmo potencial que o eletrodo interno. Se a montagem da câmara é totalmente protegida, o anel de guarda estará presente no volume de ar como um anel ao redor do eletrodo interno.

f) Câmaras de placas paralelas para radiação de elétron possuem as seguintes dimensões: espessura da janela de entrada de $1 \mathrm{~mm}$ ou menos; distância entre os eletrodos interno e externo de $2 \mathrm{~mm}$ ou menos e diâmetro do eletrodo interno (coletor) de $20 \mathrm{~mm}$ ou menos.

Este arranjo das câmaras de ionização de placas paralelas é projetado para ser utilizado com a janela de entrada posicionado em frente à fonte de radiação $X^{14}$. A FIG. 3 mostra o esquema interno de uma câmara de ionização de placas paralelas.

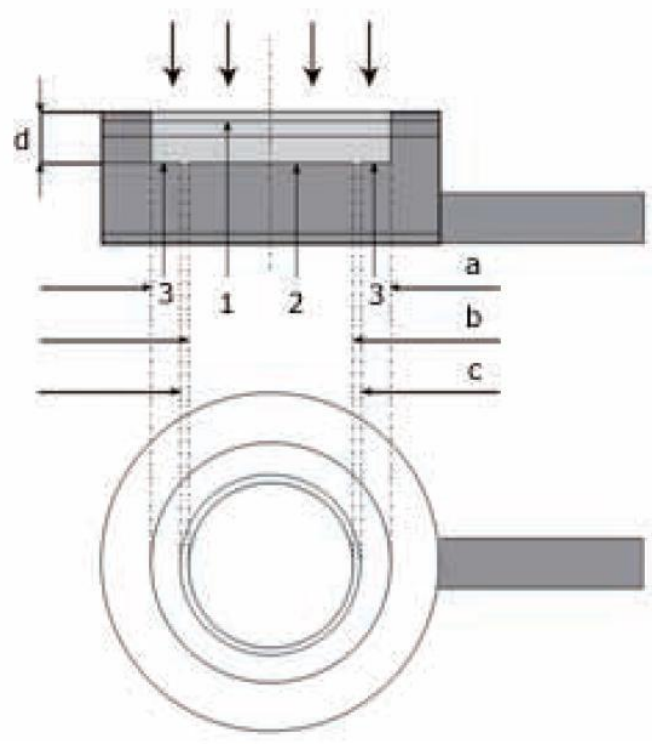

Figura 3. Esquema de uma câmara de ionização de placas paralelas. 1- Eletrodo de polarização; 2Eletrodo de medida; 3- Anel de guarda; (a) diâmetro do eletrodo de polarização; (b) diâmetro do eletrodo coletor; (c) diâmetro externo do anel de guarda; (d) altura da cavidade de ar. (1)

\subsubsection{Câmaras Cavitárias}

As câmaras cavitárias são simples e versáteis, o que permite o seu uso rotineiro. Consistem basicamente de um eletrodo central circundado por uma parede, delimitando o seu volume preenchido pelo gás. Ao entrar na câmara através da janela de entrada, a radiação interage com o material da janela, com a parede ou 
com o próprio gás, causando principalmente ionizações e excitações. Com a aplicação de um campo elétrico entre o eletrodo central e a parede, os elétrons gerados nas ionizações migram em direção ao eletrodo central, sendo coletados, enquanto que os íons positivos migram para a parede, gerando, assim, uma variação na carga do circuito. Essa variação gera um sinal elétrico que é medido por um circuito eletrônico e sua intensidade depende do número de pares de íons produzidos. As câmaras cavitárias são muito compactas se comparadas com as câmaras de ar livre, pois a condição de equilíbrio de partículas carregadas é facilmente assegurada com a utilização de um material sólido como a parede da câmara de ionização e/ou a janela de entrada ${ }^{12}$. A FIG. 4 mostra o esquema interno de uma câmara de ionização cavitária.

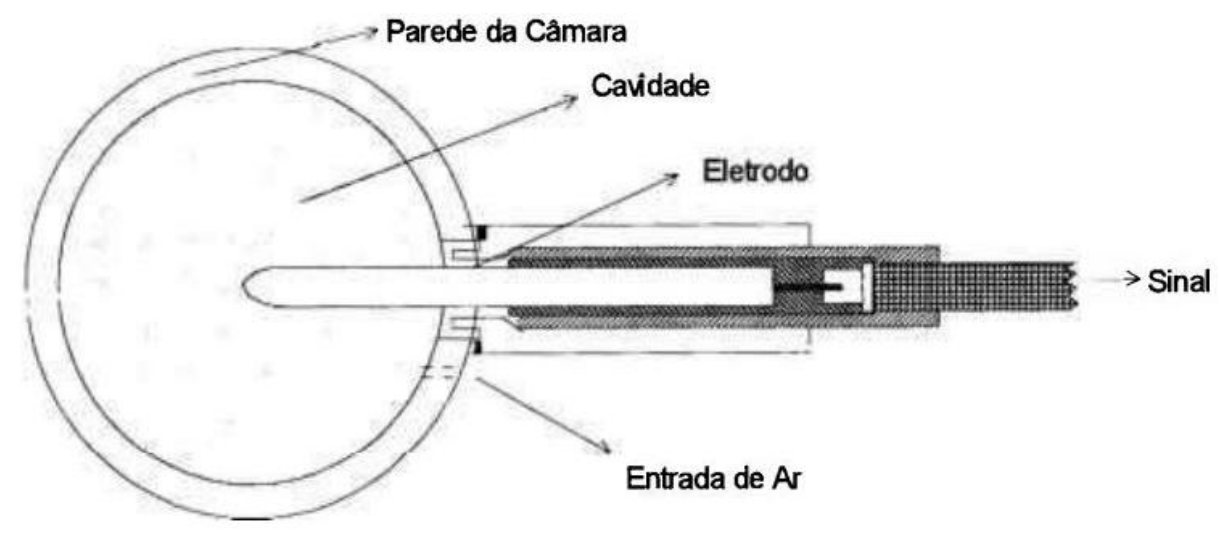

Figura 4. Esquema de uma câmara cavitária ${ }^{12}$

\subsubsection{Câmaras de Extrapolação}

A câmara de extrapolação tem sido usada de muitas formas e para diversos propósitos, variando-se sempre a distância entre os eletrodos planos e paralelos, para permitir a medida da intensidade de radiação em função da espessura da camada de ar da câmara. O propósito desta câmara é medir a dose absorvida superficial de um material sob irradiação. O volume ativo é uma pequena região em forma de moeda acima do eletrodo coletor central, que é rodeado por um anel de guarda largo. O eletrodo superior é constituído por uma folha fina presa por um anel rígido; a distância entre os eletrodos pode ser variada precisamente por meio de um parafuso micrométrico externo. Pela medida da ionização, por unidade de volume de ar, em função da distância entre os eletrodos, e extrapolando-se a curva resultante para a distância nula, pode-se obter uma boa medida da taxa de dose absorvida sob 
determinada espessura de material da janela. Esta câmara é especialmente recomendada para a detecção de radiação beta e de radiação $X$ de baixas energias, sendo utilizados materiais diferentes para os eletrodos coletores ${ }^{12}$. A FIG. 5 mostra o esquema interno de uma câmara de extrapolação.

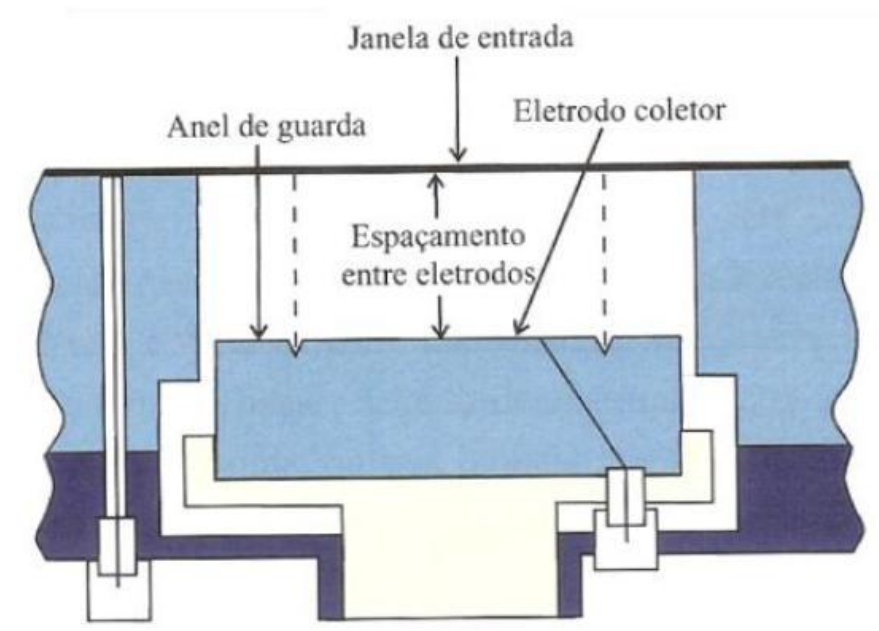

Figura 5. Esquema de uma câmara de extrapolação ${ }^{12}$

\subsubsection{Câmaras de Transmissão}

Câmaras de transmissão são utilizadas para monitoração de dose em instalações de calibração de instrumentos.

Consistem, geralmente, de camadas de PMMA (polimetil-metacrilato) cobertos com material condutor. O material condutor mais comum é o grafite, sendo próximo do equivalente do ar e introduzindo menor dependência energética para medições de kerma no ar. A cobertura de grafite é, entretanto, inconveniente para câmaras de transmissão uma vez que não é transparente à luz. Materiais transparentes à luz contêm um elevado número atômico, tais como o índio e o estanho, dando origem a uma dependência energética relativamente forte comparada com câmaras revestidas por grafite ${ }^{1}$. 

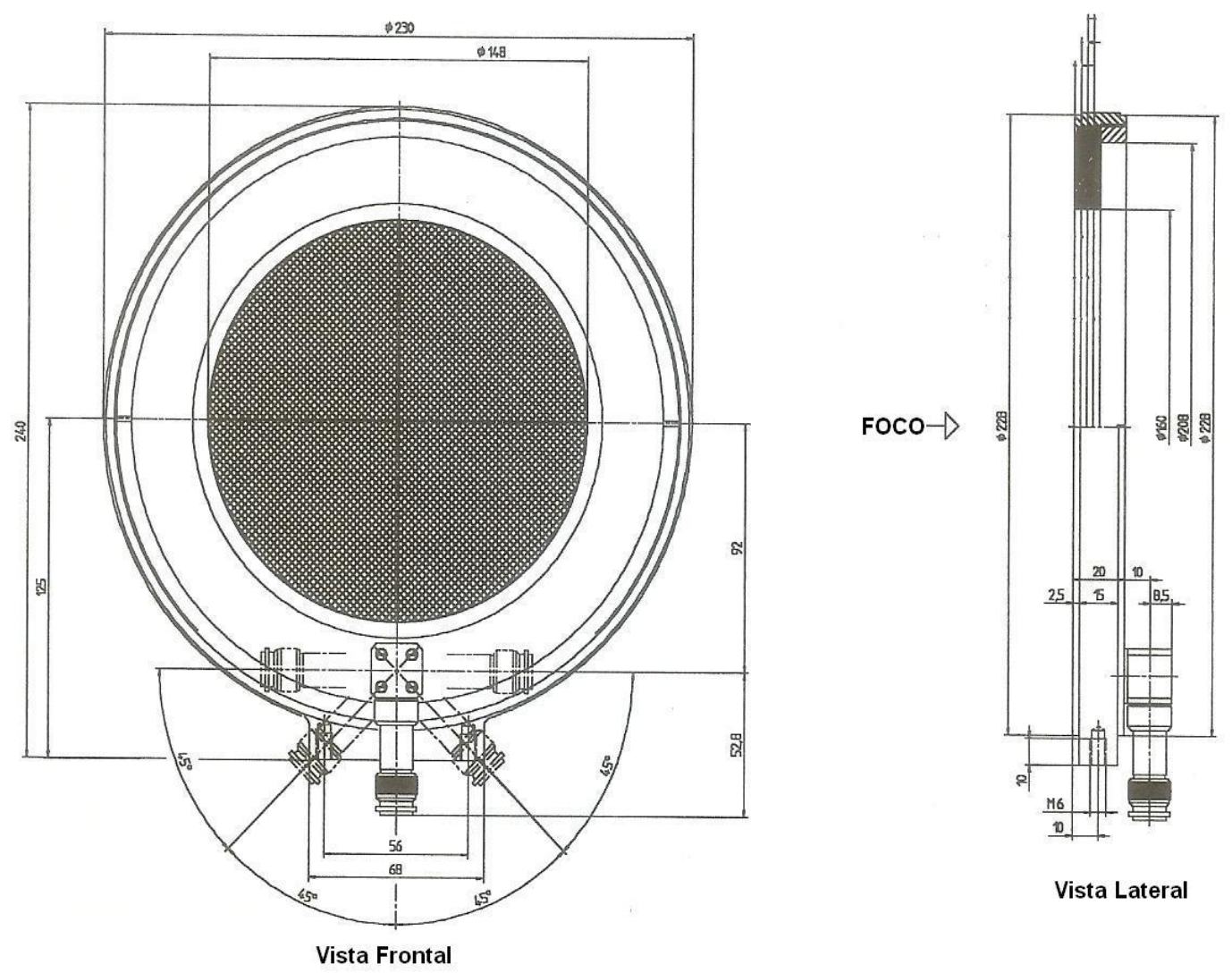

Figura 6. Esquema de uma câmara de transmissão. O diâmetro útil do campo de medida da câmara acima é de $155 \mathrm{~mm}$. Esta câmara possui dois volumes de medida iguais com diâmetro de $2 \times 2,5 \mathrm{~mm}$ x $148 \mathrm{~mm}$. O diâmetro externo mede $230 \mathrm{~mm}$. A janela de entrada é revestida de grafite com poliamida. O eletrodo é uma lâmina de poliamida revestida com grafite ${ }^{15}$

\subsubsection{Medidor Dose Area Product (DAP)}

Um medidor DAP fornece uma monitoração contínua da saída do tubo de raios $\mathrm{X}$ e uma indicação de dose absorvida em pontos de referência da pele, assim como a possibilidade de cálculo da dose de órgãos para procedimentos padrões. Pode ser usado ainda como normalização de quantidades para que quantidades dosimétricas relevantes sejam obtidas, tais como doses nos órgãos, com a utilização de coeficientes de conversão ${ }^{16}$.

Trata-se de um equipamento projetado para medições durante o exame de raios $X$ que utiliza câmaras de ionização para medições do PKA ou da taxa de PKA e kerma no ar ou taxa de kerma no ar, no feixe de um equipamento de raios $X$ usado para fins de diagnóstico médico ${ }^{7}$. Este tipo de câmara mede o produto da dose absorvida no ar (ou exposição) pela área útil do feixe e determina a energia 
transferida ao paciente. Como, em alguns casos, esta câmara é fixa, sua resposta varia de acordo com alterações eventuais na intensidade do feixe de radiação $X$.

O componente de medida do sistema consiste em uma câmara de ionização de transmissão de área extensa que é fixada na caixa de abertura para monitorar a intensidade e o tamanho do campo do feixe de um tubo de raios X. A câmara é conectada a uma unidade leitora que fornece a tensão de polarização necessária e transmite uma leitura digital do PKA. O sistema causa interferência mínima ao exame e é ideal para realizar medições de dose rotineiras, considerando calibrações adequadas em termos de quantidade de dose apropriada ao paciente ${ }^{17}$. A FIG. 7 mostra o esquema interno de um DAP.

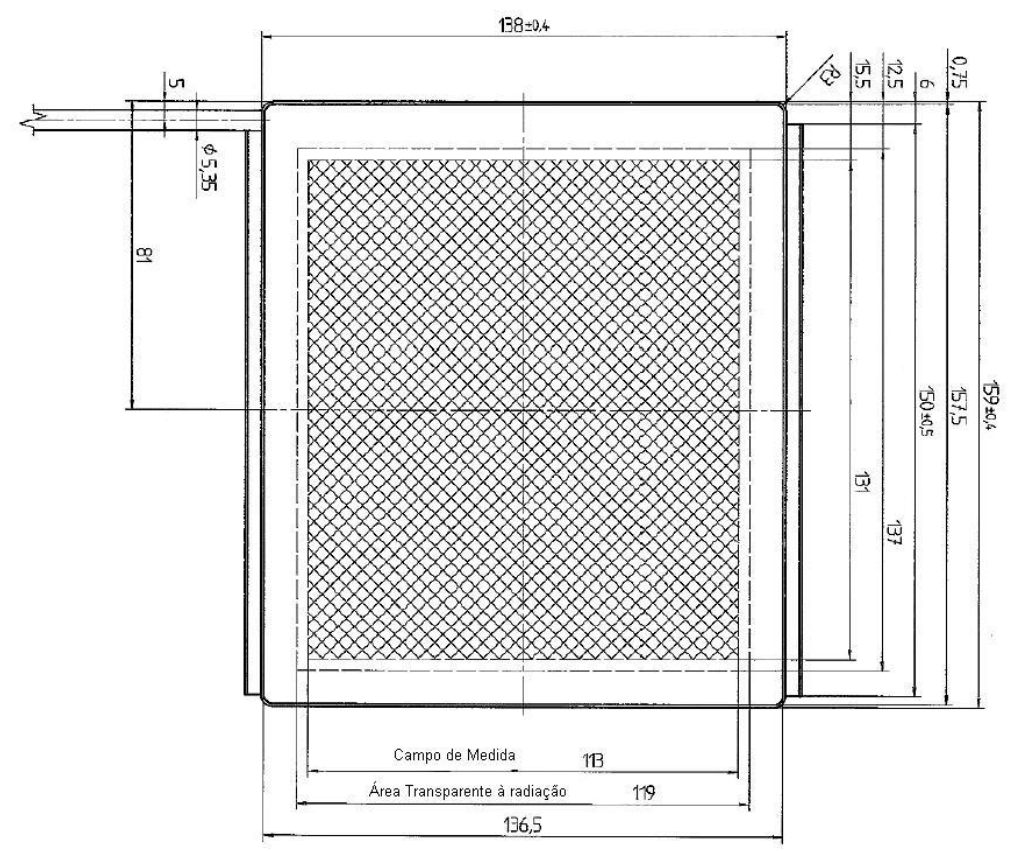

Figura 7. Esquema de um medidor DAP ${ }^{15}$

\subsubsection{Patient Dose Calibrator}

O Patient Dose Calibrator (PDC) é um equipamento que foi desenvolvido para verificar a calibração de medidores do produto kerma-área e kerma no ar usados na dosimetria de pacientes. Também pode ser utilizado para estabelecer doses de referência e níveis do produto kerma-área para exames específicos e para verificação da consistência e do comportamento de sistemas de controle de exposição automáticos. 
O PDC não é um equipamento médico; é um instrumento de medição laboratorial e não deve ser usado com pacientes.

A proteção que reveste o PDC é feita de plástico ABS. É alimentado por uma bateria interna de lítio-íon (Li-ION). Para carregar a bateria, um carregador especial com características de tensão de segurança muito baixa deve ser utilizado.

A câmara de ionização e o sistema eletrônico são componentes altamente sensíveis e devem ser manuseados com cuidado.

O PDC foi desenvolvido para funcionar como um instrumento independente, uma vez que o leitor está localizado no próprio equipamento e que é alimentado por bateria, sem a necessidade do uso de fios elétricos. Um suporte de elevação de isopor é fornecido para elevar o PDC das estruturas que podem causar radiação retroespalhada para uma medição com feixe primário. A FIG. 8 mostra o PDC posicionado no suporte em 1 e detalhes do suporte em 2.

O PDC consiste em uma montagem de câmara de ionização, placa de circuito eletrônico impresso incorporando o monitor, chave do painel e bateria. Os componentes são abrigados dentro de um revestimento protetor que incorpora o alvo de alinhamento do feixe.

A câmara de ionização está suspensa dentro do revestimento de proteção do PDC para minimizar alterações durante o posicionamento do PDC no feixe de raios $X$. A câmara consiste de áreas ativas centrais e periféricas. A medida de dose usa somente a área central enquanto ambas as áreas são usadas para medidas do PKA.

O desenho de um alvo é fornecido para auxílio com o alinhamento do feixe de radiação. Quando um campo de luz não é disponível, uma matriz com marcadores radioopacos é fornecida para alinhamento com imagem fluoroscópica. Os marcadores estão posicionados em pontos de maior intersecção no alvo e são ilustrados por pontos vermelhos.

O PDC usa um microcontrolador para conduzir e processar instruções de dados de medições. Um gerador de alta tensão comum é usado para energizar ambas as seções de câmaras de ionização. Três eletrômetros independentes estão incorporados no sistema que são permanentemente acoplados as placas coletoras da câmara de ionização.

O operador pode usar o interruptor de troca para selecionar o modo de dose ou de PKA. Ambos estão disponíveis durante ou após a exposição à radiação $\mathrm{X}$. 
Quando o sistema percebe a radiação, o mostrador automaticamente indica dose ou taxa de PKA. No fim da exposição, o mostrador indica a dose acumulada ou a taxa de dose. É importante salientar que o mostrador está incorporado no próprio instrumento, não sendo necessário o uso de um eletrômetro externo para visualização da dose.

O usuário pode zerar manualmente o mostrador a qualquer momento. Para conveniência, existe uma função automática que zera o sistema (configuração padrão, zero automático 15 segundos após o fim da exposição à radiação).

Quando o sistema é ligado, um teste de rotina automático é realizado. Esse teste envolve o mostrador, o eletrômetro, a bateria e o zero automático do eletrômetro. A bateria é carregada com um carregador que é fornecido com o sistema. Quando carregada, fornece oito horas de operação. Se o sistema não é utilizado por um período prolongado, ele desliga automaticamente ${ }^{18}$.

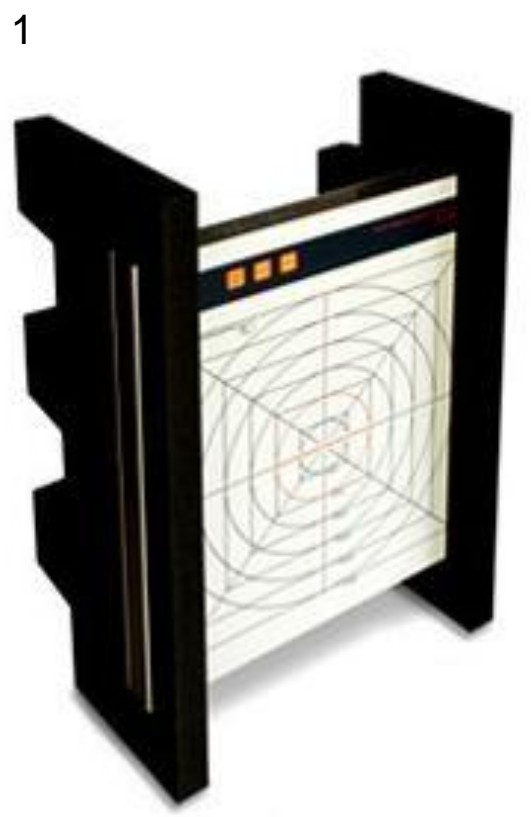

2

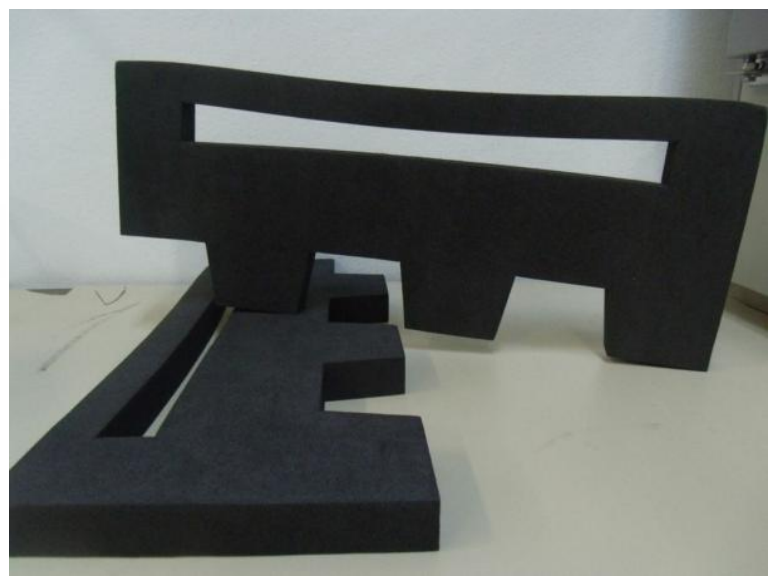

Figura 8. Em 1 o Patient Dose Calibrator e em 2 o seu suporte ${ }^{18}$

\subsection{Calibração de Instrumentos}

De acordo com o Vocabulário Internacional de Metrologia ${ }^{19}$, a calibração é definida como uma operação que estabelece, sob condições específicas, numa primeira etapa, uma relação entre os valores e as incertezas de medição fornecidos por padrões e as indicações correspondentes com as incertezas associadas; numa 
segunda etapa, utiliza esta informação para estabelecer uma relação visando a obtenção de um resultado de medição a partir de uma indicação.

Instrumentos não calibrados podem causar grandes erros na estimativa da dose. A calibração de um instrumento significa a determinação de sua resposta a uma exposição, ou ao kerma no ar, ou a uma dose absorvida de radiação, envolvendo sempre o uso de pelo menos um instrumento padrão ou de referência. $O$ termo "calibração" é usado algumas vezes para a determinação da taxa de exposição, ou taxa de kerma no ar, ou taxa de dose absorvida num ponto de referência de um feixe de radiação sob condições específicas.

Os principais objetivos de um sistema de calibração são:

a) Garantir que o instrumento esteja funcionando devidamente e de maneira adequada para o propósito a que foi projetado.

b) Determinar, sob condições padrões controladas, a indicação de leitura do instrumento como uma função do valor real medido por meio de um instrumento padrão.

c) Submeter o instrumento a testes, como resposta à energia e direção da radiação, efeitos ambientais, etc.

d) Ajustar o instrumento, se possível, para que a precisão da medida seja otimizada.

e) Fornecer padrões de radiação para testes de novos detectores ${ }^{20}$.

Existem dois métodos mais utilizados na calibração de instrumentos que medem radiação. O primeiro método é o da substituição, e é normalmente utilizado em sistemas que utilizam radiação $X$. Como o tubo de raios $X$ é um equipamento elétrico, ele está sujeito a oscilações na rede de alimentação. Um pico de energia na rede elétrica pode ocasionar um aumento na produção de radiação, causando variação na leitura do aparelho a ser calibrado.

Por conta disso, a câmara de referência é posicionada na frente do feixe, e medições são realizadas. Retira-se essa e coloca-se o aparelho a ser calibrado, e as cargas são coletadas. A primeira câmara (de referência) é, então, posicionada novamente no feixe, e novas medições são feitas. Depois de realizadas todas as correções necessárias, é gerado um coeficiente de calibração, que deve ser utilizado na câmara calibrada sempre que esta for utilizada para realizar medições. Este coeficiente é obtido dividindo-se o valor de referência pela leitura realizada pelo 
equipamento, aplicando as correções necessárias (como o fator de correção de temperatura e pressão), e sua unidade depende das unidades dos valores utilizados. Calibrações de dosímetros diagnósticos devem ser realizadas pelo método da substituição.

O segundo método de calibração mais utilizado é o dos campos bem conhecidos, mais empregado em sistemas que utilizam fontes radioativas, embora no caso de dosímetros clínicos também seja usado o primeiro método. $O$ decaimento dessas fontes é um processo bem conhecido. Após a fonte ser colocada no local adequado onde as calibrações serão feitas é realizada uma varredura no campo, para determinar a taxa de dose a diferentes distâncias. Conhecidas então as características desse campo, e sabendo que ele não sofre mudanças em razão de alterações de temperatura, pressão atmosférica, decaimento da fonte, geometria, a câmara pode simplesmente ser posicionada no feixe e as medições são realizadas. No final, é emitido um certificado com o coeficiente de calibração do equipamento ${ }^{1}$.

A calibração deve ser sempre realizada em laboratórios credenciados, rastreados à rede nacional ou internacional de metrologia das radiações ionizantes, nas qualidades adequadas para o uso do instrumento. A periodicidade da calibração de instrumentos é determinada por normas e recomendações nacionais.

Uma calibração pode ser expressa por meio de uma declaração, uma função de calibração, um diagrama de calibração, uma curva de calibração ou uma tabela de calibração. Em alguns casos, pode consistir de uma correção aditiva ou multiplicativa da indicação com uma incerteza de medição associada.

Convém não confundir a calibração com o ajuste de um sistema de medição, frequentemente denominado de maneira imprópria de "autocalibração", nem com a verificação da calibração ${ }^{19}$.

\subsubsection{Instalação para a calibração de câmaras do PKA de acordo com a TRS 457}

Uma abertura circular ou quadrada de chumbo com diâmetro ou largura conhecidos, entre 40 e 60 mm, deve estar disponível. O laboratório deve ser capaz de posicionar esta abertura em frente ao plano de medida. A distância adequada entre a abertura e o plano de medida é de $50 \mathrm{~mm}$. É necessário prever a localização da câmara do PKA nas posições I e II da FIG. 9. A exata localização da câmara do 
PKA na posição I não é de grande importância. A única exigência é que esteja em algum lugar entre a câmara de transmissão e a abertura quadrada, numa distância $d_{a}$ do ponto focal.

Na posição I, não é necessário conectar a câmara do PKA eletronicamente. Seu propósito no feixe é de permitir que o kerma no ar seja mensurado por trás da câmara do PKA, por exemplo, atenuado pela câmara do PKA. Este método de calibração assegura que o medidor do PKA, quando utilizado clinicamente, meça o produto kerma-área no feixe por trás da câmara do PKA (mede a radiação transmitida). Caso seja necessária a medição do PKA para radiação incidente no detector, a câmara do PKA deverá ser posicionada em II durante a calibração.

Na posição II, o plano de entrada da câmara do PKA, que é considerado o plano de referência da câmara, deve ser posicionado no plano de medida a uma distância $d_{r}$ do ponto focal. Valores recomendados para as distâncias $d_{a}$ e $d_{r}$ são de $950 \mathrm{~mm}$ e de $1000 \mathrm{~mm}$. Para medições de kerma no ar no plano de medida com a câmara do PKA na posição I, uma câmara de referência deve ser disponibilizada com uma área de seção transversal menor do que a área de seção transversal da abertura. Para a calibração de medidores do PKA, as qualidades de radiação para o intervalo de RQR (40 kV a $150 \mathrm{kV}$ ) devem ser utilizadas ${ }^{1}$.

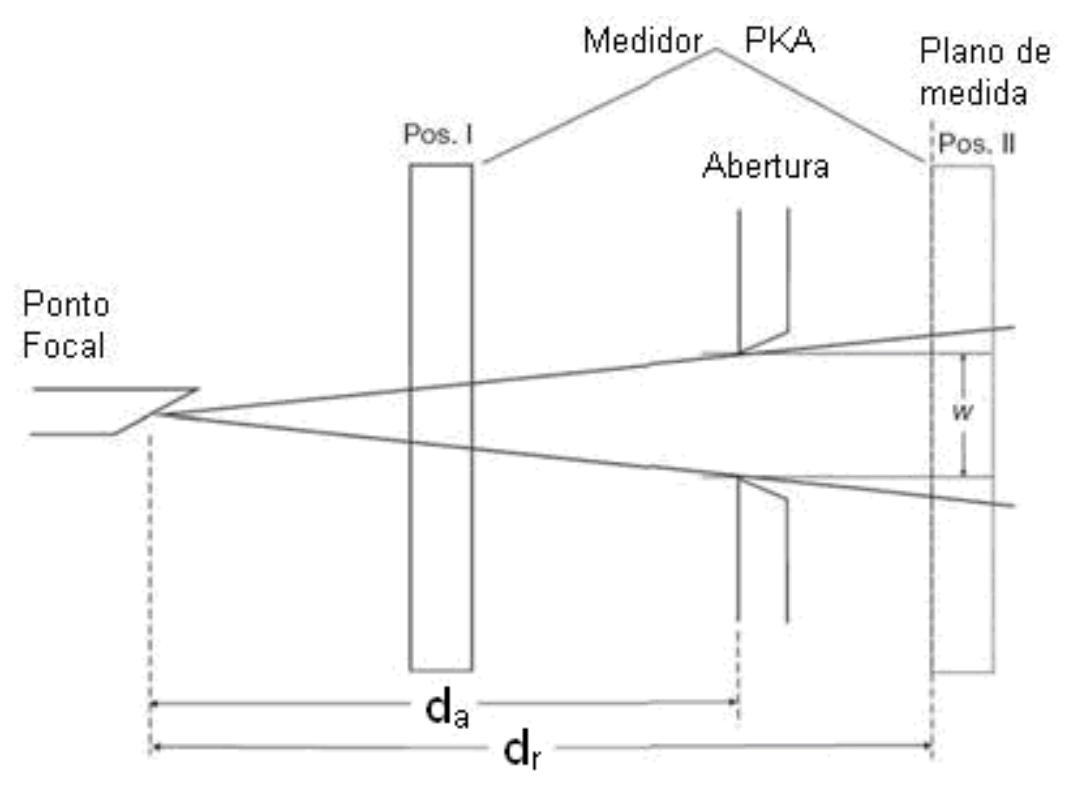

Figura 9. Arranjo para calibração de medidores do $P K A^{1}$ 


\subsubsection{Calibração de medidores do PKA em termos do produto kerma-área para radiação transmitida e incidente de acordo com a TRS $457^{1}$}

A calibração de medidores do PKA em termos de kerma no ar para radiação transmitida através da câmara é aplicável para medidores de uso clínico.

A calibração consiste de duas etapas:

a) Determinação do kerma no ar $(K)$, no plano de medição a uma distância $d_{r}$ do ponto focal no feixe com a câmara na posição I como mostra a FIG. 9;

b) A câmara é removida da posição I e posicionada na II. Seu plano de entrada é localizado no plano de medição. $O$ coeficiente de calibração para a qualidade de radiação $Q, N_{P K A, Q}$, é obtido pela leitura $M$ da câmara de PKA por:

$$
N_{P K A, Q}=\frac{K A\left(d_{r} / d_{a}\right)^{2}}{M_{P K A} k_{T P}^{\text {PKA }}}
$$

Onde $\mathrm{k}_{\mathrm{TP}}^{\mathrm{PKA}}$ é a densidade da correção do ar aplicada para a leitura de MPKA do medidor do PKA, A é a área de abertura da seção transversal e MPKA é dado por unidade de carga ou produto kerma-área e por:

$$
\mathrm{N}_{\mathrm{PKA}, \mathrm{Q}}=\frac{\dot{\mathrm{K}} \mathrm{A}\left(\mathrm{d}_{\mathrm{r}} / \mathrm{d}_{\mathrm{a}}\right)^{2}}{\mathrm{M}_{\mathrm{PKA}} \mathrm{k}_{\mathrm{TP}}^{\text {PKA }}}
$$

Onde $\mathrm{M}_{\mathrm{PKA}}$ é dado por unidade de corrente ou de taxa de produto kerma-área.

Já para radiação incidente, a calibração de medidores do PKA deve ser usada para medidores instalados em equipamentos clínicos de raios X. A forma de calibração é a mesma para radiação transmitida com exceção para medições de kerma no ar, que deve ser feito na ausência da câmara do PKA. As equações 5 e 6 devem ser usadas ${ }^{1}$.

\subsubsection{Calibração in situ}

Clinicamente, medidores do PKA são montados na saída do tubo de raios $\mathrm{X}$. Toda a radiação $X$, focal e extrafocal, passam através do volume sensível do medidor do PKA. A radiação transmitida através da câmara passará pelo plano 
perpendicular ao eixo central do feixe, desconsiderando a atenuação do ar. Se a integração do kerma no ar sobre a área do feixe for extendida por todo o plano, a integral será invariante com a distância do tubo de raios $X$ e a geometria do coeficiente de calibração pode ser derivada.

Máquinas modernas de raios $X$ diagnóstico são, geralmente, equipadas com um medidor do PKA acoplado. É importante que hospitais que possuem equipamentos como estes tenham os medidores do PKA calibrados para todas as situações clínicas relevantes na qual os equipamentos serão utilizados. A calibração de todos os medidores do PKA em laboratórios padrão secundário não é comum e, em muitos casos, não é sequer possível. Os medidores do PKA devem ser calibrados in situ utilizando um método aplicável.

Quando a calibração de medidores do PKA clínicos for realizada, o produto kerma-área deve ser determinado para o feixe de radiação transmitido através da câmara e incidente no paciente. A câmara de transmissão reduz o kerma no ar por, aproximadamente, 15 a 20\%. Para medidores instalados abaixo da mesa de exames, a atenuação na mesa de exames do paciente deve ser considerada e calibrações in situ devem ser realizadas separadamente para instalações abaixo e acima da mesa de exames.

Deve haver a percepção de que, quando um medidor do PKA é utilizado num equipamento instalado abaixo da mesa de exames, a correção é necessária para atenuação da mesa e para uma possível radiação espalhada do paciente e da própria mesa. A atenuação pela mesa de exames pode ser estimada em 15 a 30\% para as qualidades de radiação com uma camada semirredutora de 2 a $7 \mathrm{~mm}$ de alumínio.

De acordo com o TRS 457, duas formas de calibração in situ de medidores do PKA podem ser adotadas. O primeiro método utiliza um dosímetro diagnóstico para medições de kerma no ar no plano de referência com o feixe e com a área previamente conhecida. O segundo método utiliza um medidor do PKA de referência, calibrado num laboratório padrão secundário, para a calibração de medidores do PKA clínicos. O segundo método foi o utilizado para este trabalho. 


\subsubsection{Calibração in situ com um dosímetro diagnóstico}

O produto kerma-área é determinado como o produto do kerma no ar no eixo central e na área nominal do feixe. Para todas as qualidades de radiação, a câmara do PKA é exposta para um tamanho de campo fixo e sua indicação é medida junto com a indicação do dosímetro diagnóstico de referência posicionado no plano de medida. Uma área de $100 \mathrm{~mm} \times 100 \mathrm{~mm}$ na posição do dosímetro diagnóstico é recomendada.

a) Para instalações acima da mesa de exames:

1- Monte o medidor do PKA na saída do feixe e conecte-o ao eletrômetro. Caso a instalação possua um medidor acoplado, use o dispositivo interno.

2- Posicione o detector do dosímetro diagnóstico calibrado no eixo central e a $200 \mathrm{~mm}$ acima da mesa de exames a fim de evitar a influência da radiação espalhada.

3- Colime o feixe de raios $X$ para que sua área, na posição do detector seja de aproximadamente $100 \mathrm{~mm} \times 100 \mathrm{~mm}$.

4- Exponha o detector e o medidor do PKA utilizando todas as combinações de tensão do tubo e filtração total que são usadas em aplicações clínicas.

5- Registre os sinais do medidor do $\mathrm{PKA}, \mathrm{M}_{\mathrm{Q}}^{\mathrm{PKA}}$, do dosímetro de referência, $\mathrm{M}_{\mathrm{Q}}^{\mathrm{ref}}$.

Para sistemas tela-filme

6- Remova a câmara de referência e posicione o filme cassete perpendicular ao eixo central na posição do detector de referência.

7- Exponha o filme cassete. A densidade óptica máxima não deve exceder 0,5.

8- Revele o filme e determine a área nominal do feixe $A$ na área que está dentro de $50 \%$ da densidade óptica máxima.

Para sistemas de radiografia computadorizada

6- Remova a câmara de referência e posicione o cassete de radiografia computadorizada perpendicular ao eixo central na posição do detector de referência.

7- Exponha o cassete. 
8- Produza uma cópia da imagem e determine a área nominal do feixe, $A$, sendo a área que esteja dentro de $50 \%$ do valor máximo de pixel.

O coeficiente de calibração, $\mathrm{N}_{\mathrm{PKA}, \mathrm{Q}}$, é calculado a partir das leituras de $\mathrm{M}_{\mathrm{Q}}^{\mathrm{PKA}}$ e de $\mathrm{M}_{\mathrm{Q}}^{\mathrm{ref}}$ (corrigido para densidade do ar se necessário) e a área nominal do feixe

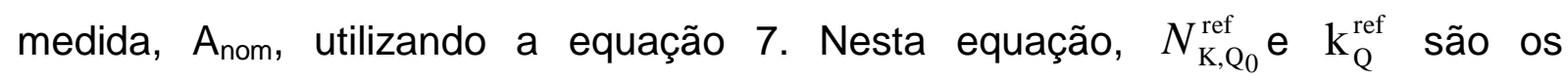
coeficientes de calibração do dosímetro de referência obtidos na qualidade do feixe $Q_{0}$ e o fator de correção da diferença de resposta entre as qualidades $Q_{0}$ e $Q$. Este cálculo se aplica a instalações acima e abaixo da mesa de exames.

$$
\mathrm{N}_{\mathrm{PKA}, \mathrm{Q}}=\frac{M_{Q}^{r e f}}{M_{Q}^{P K A}} N_{\mathrm{K}, \mathrm{Q}_{0}}^{\mathrm{ref}} \mathrm{k}_{\mathrm{Q}}^{\mathrm{ref}} \mathrm{A}_{\mathrm{nom}}
$$

b) Para instalações abaixo da mesa de exames:

O valor de PKA deve representar o feixe incidente no paciente e, assim, levar em consideração a atenuação da mesa de exames, assim como, o espalhamento causado pela mesa que deve atingir o paciente. A mesa de exames pode reduzir o PKA num valor de 15 a 30\%, comparado com medições acima da mesa. Para calibrações abaixo da mesa de exames, o detector deve ser posicionado sobre a mesa para refletir a atenuação do feixe e a radiação espalhada pela mesa. $O$ arranjo de calibração é mostrado na FIG. 10. As etapas 3-8 que descrevem o procedimento de calibração para instalações acima da mesa de exames são também seguidas para situações onde a instalação é abaixo da mesa de exames ${ }^{1}$. 


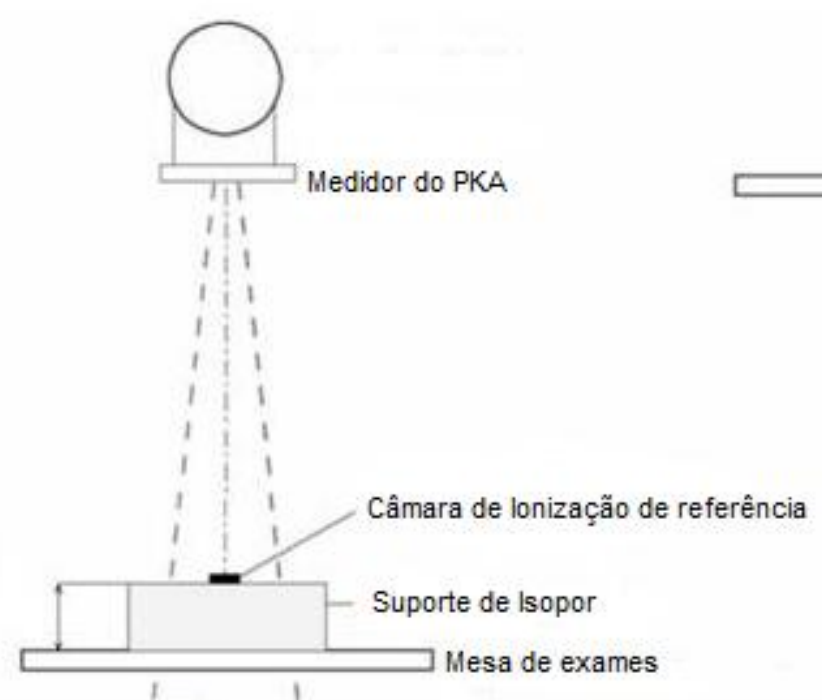

A

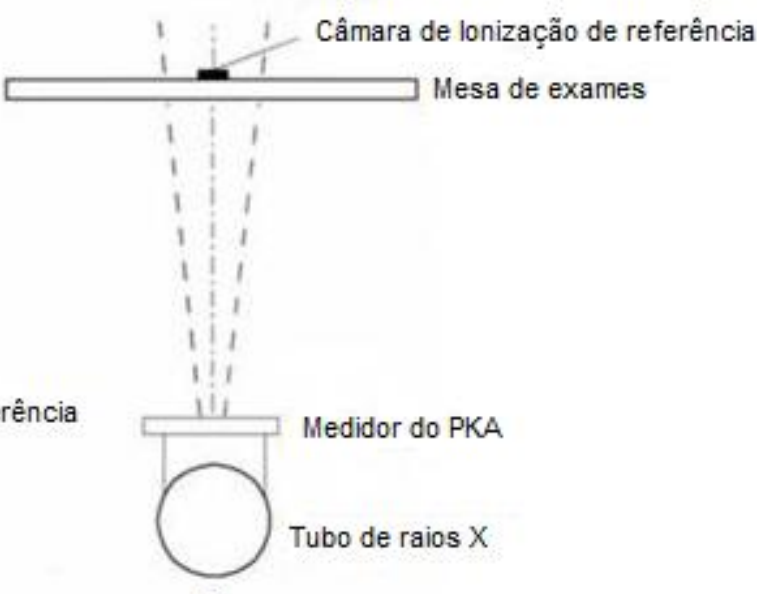

B

Figura 10. Arranjo para calibração de medidores do PKA in situ ${ }^{1}$

\subsubsection{Calibração in situ com um medidor do PKA de referência}

Um medidor do PKA de referência, calibrado num laboratório padrão secundário, pode ser utilizado para calibração de medidores do PKA num hospital. A calibração de um medidor do PKA de referência é necessária para a faixa de qualidades de radiação caracterizadas pelo valor de suas camadas semirredutoras. A calibração entre dois pontos pode ser interpolada para se obter um coeficiente de calibração para as qualidades de radiação disponíveis no hospital. Extrapolações acima da camada semirredutora no certificado de calibração não são recomendadas.

A interpolação entre dois pontos de calibração para o medidor do PKA de referência pode ser utilizada para filtrações totais de até $3 \mathrm{~mm}$ de alumínio, independente da tensão do tubo de raios X. Para feixes com maiores filtrações, ambos, camada semirredutora e tensão do tubo devem ser exigidos para realizar a interpolação.

O arranjo deste método é o mesmo para a calibração com o dosímetro diagnóstico, exceto pela substituição do dosímetro pelo medidor do PKA de referência. $O$ procedimento de calibração é realizado da seguinte maneira: $O$ coeficiente de calibração, $\mathrm{N}_{\mathrm{PKA}, \mathrm{Q}}$, é calculado a partir das leituras de $\mathrm{M}_{\mathrm{Q}}^{\mathrm{PKA}}$ e $\mathrm{M}_{\mathrm{Q}}^{\mathrm{PKA} \text { ref }}$ (corrigido para temperatura e pressão), utilizando a equação 8. Nesta 
equação, $\mathrm{N}_{\mathrm{PKA}, \mathrm{Q}_{0}}^{\mathrm{ref}}$ é o coeficiente de calibração do medidor do PKA de referência obtido na qualidade do feixe $\mathrm{Q}_{0}$ e $\mathrm{k}_{\mathrm{Q}}^{\text {ref }}$ é o fator de correção da diferença de resposta entre as qualidades do feixe $Q_{0}$ e $Q$.

$$
N_{P K A, Q}=\frac{M_{Q}^{P K A_{\text {ref }}}}{M_{Q}^{P K A}} N_{{\mathrm{PKA}, \mathrm{Q}_{0}}_{\mathrm{Q}}^{\mathrm{ref}}} \mathrm{k}_{\mathrm{Q}}^{\mathrm{ref}}
$$

\subsubsection{Calibração método tandem}

No método de calibração tandem, um medidor do PKA de campo é calibrado usando um medidor do PKA de referência. As câmaras são irradiadas simultaneamente num feixe de radiação $X$ passando por ambos. O medidor do PKA de campo é usado na mesma unidade de raios $X$, posicionamento e geometria assim como as medições com pacientes, e o medidor do PKA de referência é posicionado a uma distância maior. O medidor do PKA de referência deve ser calibrado para feixes de radiação $X$ incidentes na câmara.

O medidor do PKA de campo é utilizado para indicar o valor do PKA do feixe incidente no plano de entrada do paciente. A princípio, a câmara de referência deve, portanto, ser posicionada no plano correspondente a superfície de entrada representativa do paciente. A distância entre as câmaras deve ser grande o suficiente para reduzir o espalhamento de uma câmara para a outra. Por outro lado, o tamanho do campo na câmara de referência deve ser mantido pequeno, de forma que o todo o feixe alcance a câmara. A área da câmara opera como área de integração na calibração tandem. Em geral, a proporção de radiação espalhada alcançando a câmara de referência na calibração não é a mesma que alcança o paciente em medições na prática. Assim, o conceito de valores de referência do PKA é de alguma forma vago, dando origem a uma incerteza extra na calibração de medidores do PKA de campo, se a geometria de calibração não é padronizada. De qualquer forma, a área da câmara do PKA de referência deve ser maior do que o campo de radiação nominal no plano da câmara, pois as regiões de penumbra devem ser incluídas. 
A geometria de calibração deve ser padronizada pela posição e área do medidor do PKA de referência, que deve definir tamanhos de campo ideais em distâncias típicas de pacientes.

Para geometria de irradiação sob a mesa, a câmara do PKA de referência pode ser posicionada acima da mesa do paciente. A radiação espalhada da mesa é incluída no valor de referência do PKA, nesse caso, especialmente se a câmara do PKA de referência está próxima ao topo da mesa ${ }^{5}$. 


\section{MATERIAIS E MÉTODOS}

\subsection{Materiais}

\subsubsection{Sistemas de Dosimetria}

- Sistema de referência padrão secundário, composto por uma câmara de ionização Radcal, modelo RC6, mostrado na FIG. 11, acoplada a um eletrômetro Keythley, modelo 6517. Esta câmara possui rastreabilidade ao Laboratório Alemão Primário PTB.

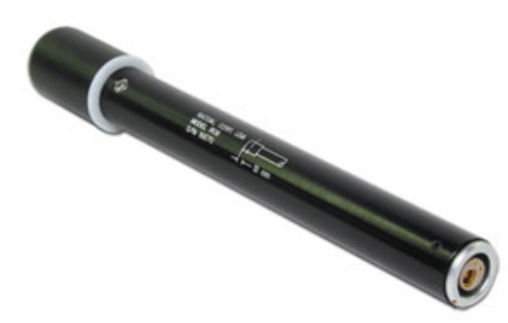

Figura 11. Câmara de lonização da Radcal modelo $R C 6^{18}$

- Câmara de lonização/Eletrômetro, da marca Radcal, modelo 20X6-3, mostrada na FIG. 12, pertencente ao Departamento de Energia Nuclear da Universidade Federal de Pernambuco - DEN-UFPE.

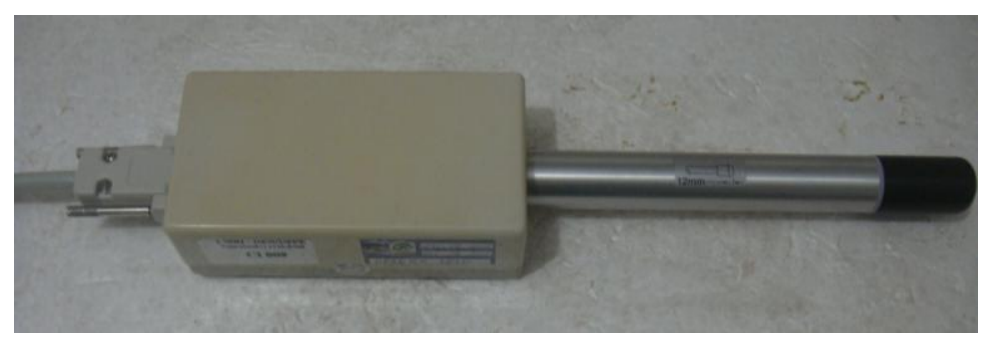

Figura 12. Câmara de lonização da Radcal modelo 20X6-3

- PDC (Patient Dose Calibrator) marca Radcal, como mostra a FIG. 8. 
- Medidor do PKA da PTW, modelo Diamentor E2, mostrado na FIG. 13, pertencente à Universidade Federal de São Paulo - UNIFESP-SP.

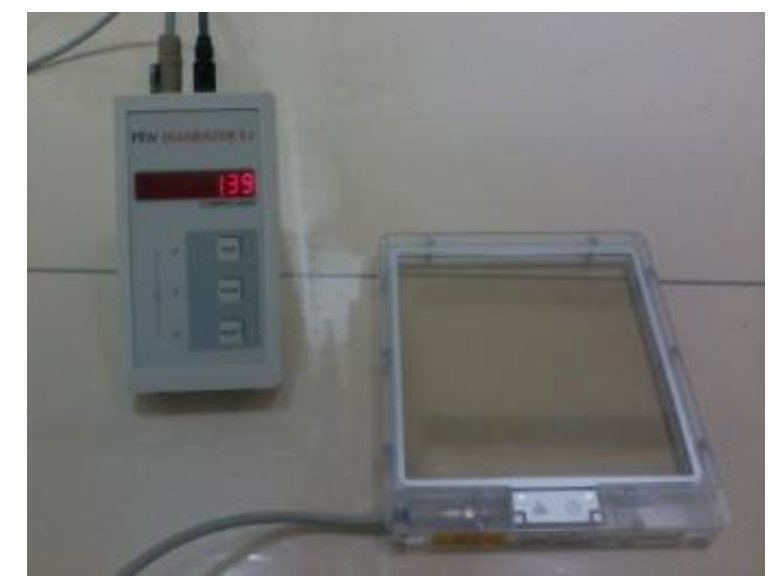

Figura 13. Medidor do PKA Diamentor E2 da Unifesp

- Medidor do PKA da IBA dosimetry, modelo KermaX® plus TinO (Two in One) 120-205, mostrado na FIG. 14, pertencente ao Instituto Federal da Bahia (IFBA), Salvador e utilizado também no Centro de Diagnóstico por Imagem (CEDRUL) em João Pessoa - PB.

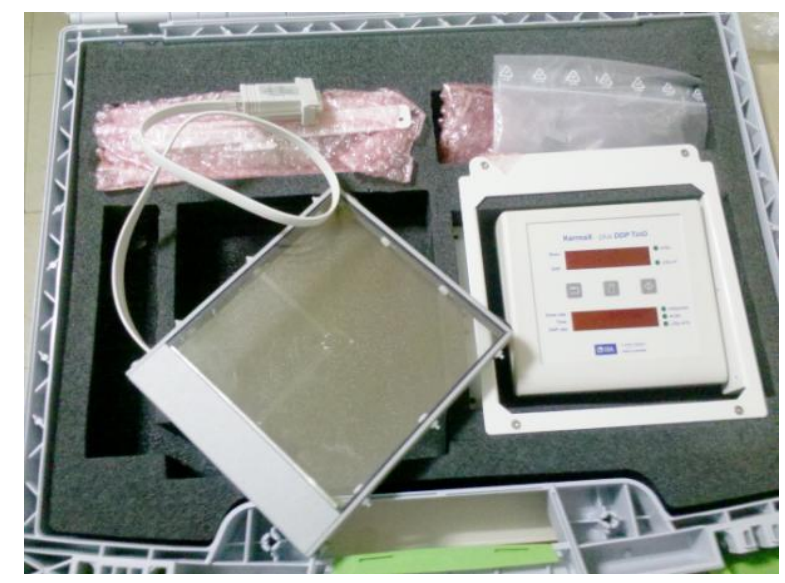

Figura 14. Medidor do PKA KermaX® plus TinO (Two in One) 120-205 do IFBA 
- Medidor do PKA da PTW, modelo Diamentor E2, mostrado na FIG. 15, pertencente ao DEN-UFPE.
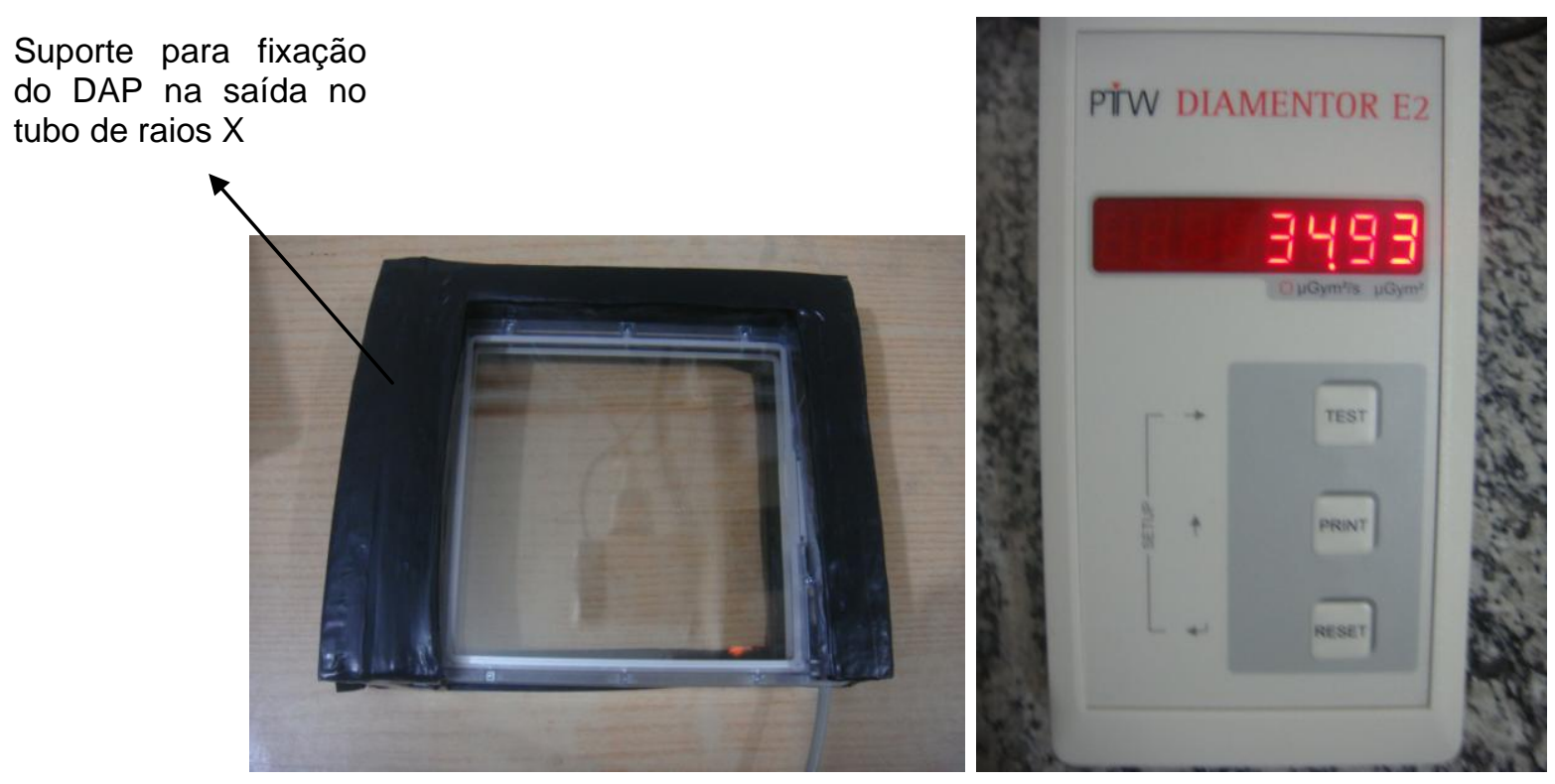

Figura 15. Medidor do PKA Diamentor E2 da UFPE

Todos os medidores do PKA utilizados não possuíam um suporte que pudesse proporcionar a fixação do mesmo na saída do tubo de raios $\mathrm{X}$, o que dificultou as medições uma vez que não é indicado que a área de leitura dos medidores receba algum tipo de fixação. Em alguns sistemas, foi necessária a utilização de fitas adesivas para esta fixação, cobrindo apenas a lateral do medidor.

\subsubsection{Sistemas de Radiação X}

- Sistema de radiação X marca Pantak/Seifert, modelo Isovolt $160 \mathrm{HS}$, mostrado na FIG. 16, na faixa de operação de radiodiagnóstico clínico (40 kV$160 \mathrm{kV}$ ). A corrente aplicada foi de $10 \mathrm{~mA}$, para as diferentes séries de qualidades implantadas, mostradas na TAB. 1, localizado no Laboratório de Calibração de Instrumentos ( $\mathrm{LCl}$ ) do Instituto de Pesquisas Energéticas e Nucleares (IPEN). 


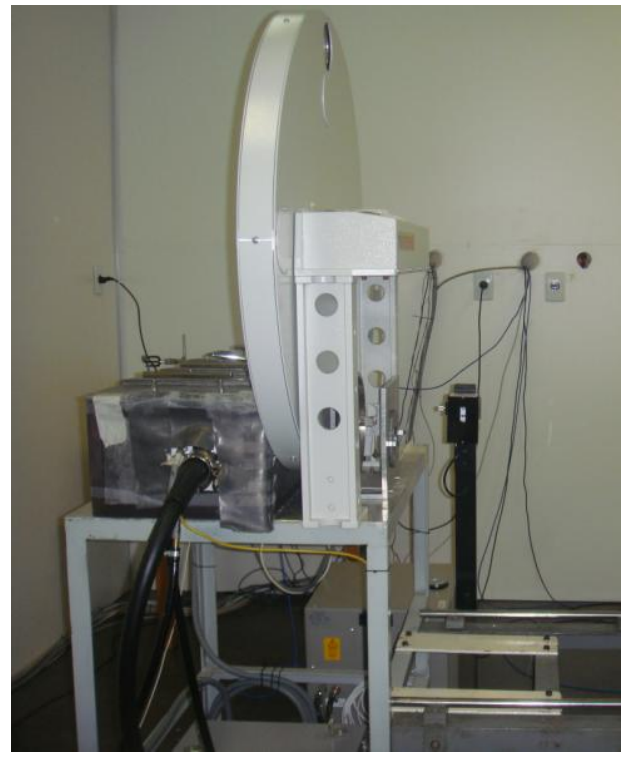

Figura 16. Sistema de Radiação X Pantak/Seifert do IPEN

Tabela 1. Qualidades de radiação estabelecidas no LCI-IPEN para radiodiagnóstico

\begin{tabular}{cc}
\hline $\begin{array}{c}\text { Qualidades } \\
\text { Implantadas }\end{array}$ & Tensão \\
\cline { 1 - 1 } $\begin{array}{c}\text { Radiologia } \\
\text { Convencional }\end{array}$ & \\
\hline RQR 3 & $50 \mathrm{kV}$ \\
RQR 5 & $70 \mathrm{kV}$ \\
RQR 8 & $100 \mathrm{kV}$ \\
RQR 10 & $150 \mathrm{kV}$ \\
& \\
Mamografia & \\
WMV/WMH 25 & $25 \mathrm{kV}$ \\
WMV/WMH 28 & $28 \mathrm{kV}$ \\
WMV/WMH 30 & $30 \mathrm{kV}$ \\
WMV/WMH 35 & $35 \mathrm{Kv}$ \\
& \\
Tomografia & \\
Computadorizada & \\
\hline RQT 8 & $100 \mathrm{kV}$ \\
RQT 9 & $120 \mathrm{kV}$ \\
RQT 10 & $150 \mathrm{kV}$ \\
\hline
\end{tabular}

- Sistema de Radiação X RAEX 300D, faixa de operação de 40 kV a 120 kV, pertencente ao IFBA, Salvador

- Sistema de Radiação X EDR 750B, faixa de operação de 30 kV a 120 kV, pertencente ao DEN-UFPE, Recife. 
- Sistema de Radiação X, Pantak Bipolar series 2, modelo HF320, faixa de operação industrial de 25 kV a 320 kV.

- Sistema de Radiação X Philips Compacto Plus 500 VMI, faixa de operação de $40 \mathrm{kV}$ a $125 \mathrm{kV}$, pertencente à UNIFESP.

- Sistema de Radiação X Intervencionista Philips Allura Xper modelo FD10, pertencente ao Hospital São Paulo.

\subsubsection{Outros equipamentos}

- Câmara de ionização de transmissão (monitora) marca PTW modelo 34014 com paredes e eletrodos de poliamida grafitada de $25 \mu \mathrm{m}$ de espessura, com diâmetro externo de $230 \mathrm{~mm}$;

- Unidade leitora de temperatura marca Hart Scientific modelo 1529-R Chub E-4;

- Barômetro digital de precisão marca Druck modelo DPI 142;

- Termistor de referência padrão secundário marca Hart Scientific modelo 5611-X ("silicone-bead probe");

- Roda de filtros marca PTW, modelo T90010/90011, com 24 posições

\subsection{Métodos}

Os testes com o PDC foram realizados de acordo com as limitações de cada equipamento de radiação $X$ estudado. A seguir serão apresentados os métodos de cada análise.

\subsubsection{Testes realizados no IPEN}

\subsubsection{Medições nas qualidades implantadas no sistema de radiação $X$}

Foram feitos testes no equipamento de radiação $X$ presente no $\mathrm{LCl}$ nas qualidades de radiação implantadas no sistema. Estes testes foram realizados com 0 PDC a $1 \mathrm{~m}$ de distância do ponto focal, posicionado com o centro do feixe direcionado ao centro do PDC, como mostra a FIG. 17. A corrente utilizada foi de $10 \mathrm{~mA}$ e foram realizadas irradiações de $30 \mathrm{~s}$ para cada qualidade de radiação. $\mathrm{A}$ 
temperatura e pressão nesse caso não foram verificadas, pois o PDC ajusta automaticamente esses fatores.

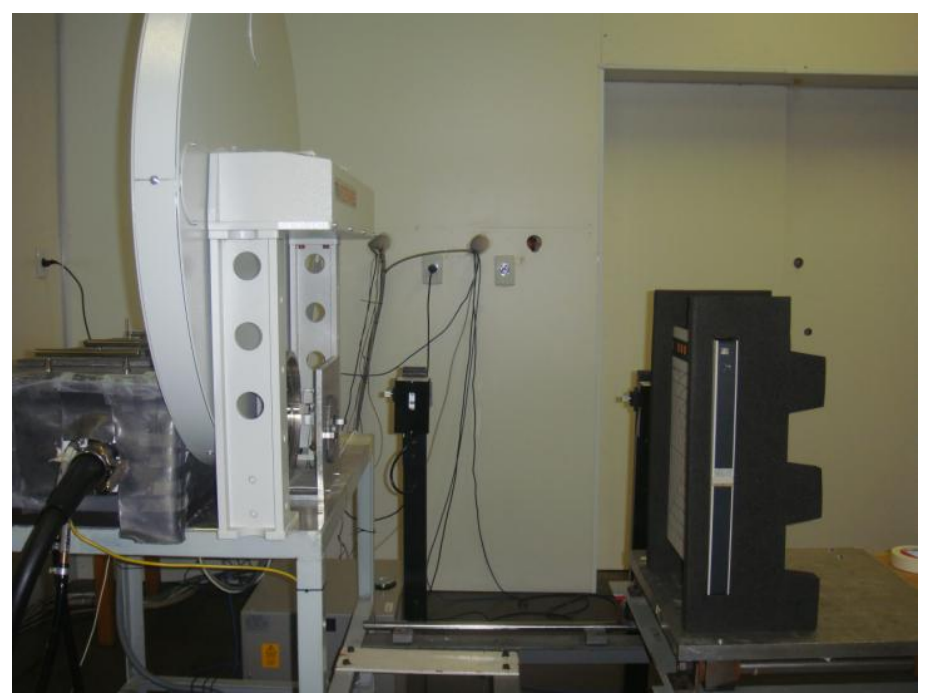

Figura 17. Medições nas qualidades de radiação implantadas no LCl

\subsubsection{Avaliação de desempenho do PDC de acordo com as normas IEC $61674^{21}$ e IEC $60580^{7}$}

Após análise do manual de instruções do PDC, testes de controle de qualidade foram realizados para caracterizá-lo e para que o mesmo indicasse seu desempenho.

O controle de qualidade do PDC foi realizado de acordo com a norma britânica BS EN 61674:1998 IEC 61674:1997²1. O capítulo cinco desta norma aborda as características de limites de desempenho de dosímetros com câmaras de ionização, que é o caso do PDC. Os itens analisados desta norma foram:

- Erro intrínseco relativo: comparação de medições em condições padrão de medida com uma média de pelo menos cinco leituras do instrumento.

- Repetibilidade: repetições de medidas sob condições inalteradas.

- Resolução de leitura: leitura de toda a faixa efetiva de valores indicados.

- Tempo de estabilização: ligar o equipamento e verificar os limites de variação de resposta.

- Reiniciar: reiniciar o equipamento e verificar a escala de leitura.

- Efeitos de fuga de corrente: níveis de fuga de corrente após algum ajuste de compensação. 
A norma IEC $60580^{7}$, específica para medidores do PKA, estabelece os requisitos para um nível satisfatório de desempenho de um medidor do PKA além de padronizar métodos para a determinação da conformidade com este nível de desempenho. Além dos testes presentes na norma IEC $61674^{21}$, a norma IEC $60580^{7}$ possui testes adicionais. Foram eles:

- Desvio de valores indicados: durante ausência de radiação e depois de zerar o equipamento, o valor indicado deve ser menor do que $10 \%$ da dose mínima efetiva do PKA por pelo menos 1 hora.

- Tempo de resposta: um valor de $90 \%$ do valor final indicado deve ser alcançado dentro de um tempo não maior do que 3 segundos após o fim da irradiação.

- Uniformidade espacial de resposta: sobre o tamanho do campo avaliado, a uniformidade espacial de resposta não deve variar mais do que $\pm 5 \%$.

\subsubsection{Calibração do PDC segundo o código de prática TRS $457^{1}$}

A calibração do PDC foi realizada pelo método descrito na seção 2.4.1 e 2.4.2. A câmara de ionização RC6, FIG. 11, foi utilizada como referência para calibração do PDC. Os valores de RQR 3, 5, 8 e 10 foram calculados com a utilização da câmara RC6. A corrente utilizada foi de $10 \mathrm{~mA}$, distância fonte-câmara de $1 \mathrm{~m}$, distância fonte-abertura de $0,91 \mathrm{~m}$, cinco irradiações de $30 \mathrm{~s}$ cada e a utilização de uma abertura de chumbo, como descrito no código de prática TRS $457^{1}$, de $4 \mathrm{~cm}^{2}$.

As medições foram realizadas da seguinte maneira:

1- Os valores de taxa de kerma para as qualidades RQR foram encontrados com a câmara de ionização RC6 posicionada a $1 \mathrm{~m}$ de distância da fonte e com a abertura de chumbo de $4 \mathrm{~cm}^{2}$ posicionada $9 \mathrm{~cm}$ em frente à câmara e, consequentemente, a $0,91 \mathrm{~m}$ da fonte de radiação X. A FIG. 18 ilustra o posicionamento da câmara. 


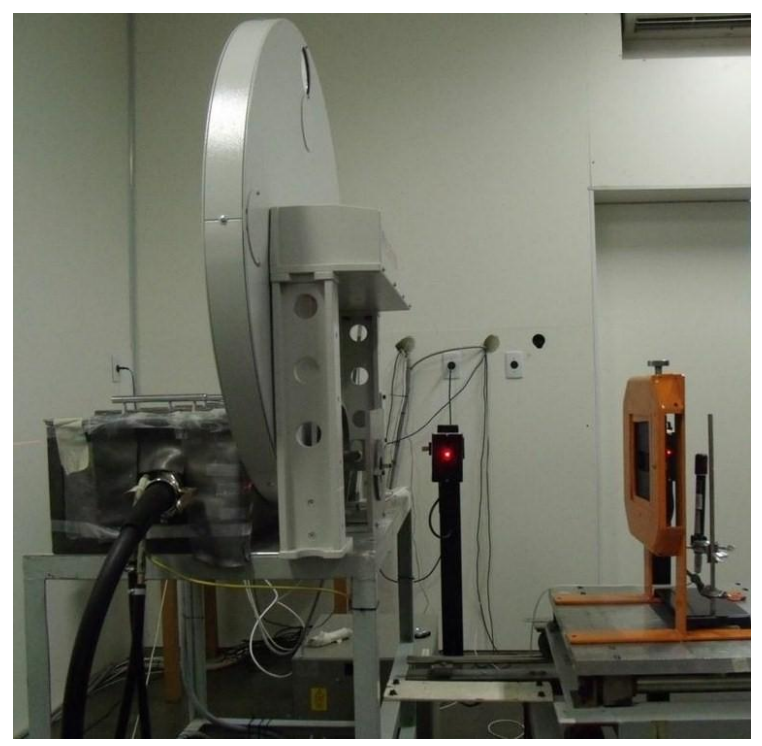

Figura 18. Posicionamento da câmara RC6 para calibração do PDC.

2- Uma vez que a câmara de ionização disponibiliza os valores na unidade de carga $(C)$, a equação 9 foi utilizada para que esses valores fossem convertidos para unidade de kerma no ar (Gy).

$$
K_{a}=N_{K}{ }^{*} M{ }^{*} k_{Q}{ }^{*} f_{T P}
$$

Onde: $N_{K}$ é o coeficiente de calibração da câmara RC6, dado por: 4,623.10 ${ }^{6} \mathrm{~Gy} / \mathrm{C}$; $M$ é a leitura da câmara; $k_{Q}$ é o fator de correção para as qualidades de radiação, mostrados na TAB. 2., e f TP é o fator correção para temperatura e pressão.

Tabela 2. Fator de Correção para a câmara de ionização padrão RC6 no sistema de radiação X do LCI do IPEN.

\begin{tabular}{cc}
\hline Qualidade de Radiação & Fator de Correção \\
\hline RQR 3 & 0,0998 \\
RQR 5 & 1 \\
RQR 8 & 1,005 \\
RQR 10 & 1,006 \\
\hline
\end{tabular}

3- Com o resultado dessa equação, dado em unidade de kerma no ar (Gy), é possível obter o valor do PKA, multiplicando-o pela área da abertura de chumbo.

4- $O$ valor de $N_{P K A, Q}$ pode ser encontrado com a equação 5 utilizando-se a distância câmara-fonte $(1 \mathrm{~m})$ como $d_{r}$ e a distância abertura-fonte $(0,91 \mathrm{~m})$ como $d_{a} e$ 
dividindo pela leitura do PDC, encontrada sob as mesmas condições da leitura da câmara RC6, substituindo-se a câmara de referência da FIG. 18, pelo PDC.

5- Os fatores de correção para as qualidades de radiação RQR 3, 5, 8 e 10 são encontrados dividindo-se o valor de $N_{P K A, Q}$ de cada qualidade pelo valor de $\mathrm{N}_{\mathrm{PKA}, \mathrm{Q}}$ de RQR 5, que é dado como referência.

\subsubsection{Avaliação da dependência energética}

A dependência energética foi avaliada com base nos dados obtidos para a calibração do PDC. O gráfico de dependência energética foi obtido a partir de dados da camada semirredutora do equipamento de raios $X$ e dos coeficientes de calibração obtidos a partir da calibração do PDC. A TAB. 3 mostra os valores de camada semirredutora.

Tabela 3. Valores de camada semirredutora do sistema de radiação $X$ do LCI do IPEN.

\begin{tabular}{cc} 
Qualidade de Radiação & $\begin{array}{c}\text { Camada Semirredutora } \\
\text { (mmAl) }\end{array}$ \\
\hline RQR 3 & 1,78 \\
RQR 5 & 2,58 \\
RQR 8 & 3,97 \\
RQR 10 & 6,57 \\
\hline
\end{tabular}

\subsubsection{Avaliação de desempenho para as qualidades de mamografia}

Testes de avaliação de desempenho do PDC foram realizados para as qualidades de mamografia. O PDC foi posicionado a $1 \mathrm{~m}$ de distância da fonte de radiação $X$, a corrente utilizada foi de $10 \mathrm{~mA}$, cinco irradiações de $30 \mathrm{~s}$ cada e, considerando as qualidades de radiação em mamografia, houve a adição de filtros específicos para mamografia, que são os de molibdênio $(0,07 \mathrm{~mm})$ para os WMV e com a adição ainda de um filtro de alumínio $(2 \mathrm{~mm})$ posicionado na saída para câmara de ionização monitora para as qualidades de WMH. As tensões correspondentes para cada qualidade de radiação WMV e WMH são de $25 \mathrm{kV}, 28$ kV, $30 \mathrm{kV}$ e $35 \mathrm{kV}$. O posicionamento do PDC foi igual ao da FIG. 17 para essas medições. 


\subsection{Calibração de medidores do PKA utilizando o PDC como referência}

Nas seções a seguir serão mostrados os laboratórios em que foram realizadas calibrações de medidores do PKA com a utilização do PDC como referência. A TAB. 4 resume as condições de irradiação para cada lugar onde houve a calibração de DAP pelo método tandem.

Tabela 4. Condições de Irradiação nos locais onde o método de calibração foi aplicado

\begin{tabular}{|c|c|c|c|c|}
\hline \multicolumn{5}{|c|}{ CONDIÇÕES DE IRRADIAÇÃO } \\
\hline & UNIFESP & CEDRUL & DEN & IFBA \\
\hline Tensões (kV) & $\begin{array}{l}50,70,100 \\
120\end{array}$ & $\begin{array}{l}50,70,100 \\
120\end{array}$ & $50,70,90$ & $50,70,90$ \\
\hline \multicolumn{5}{|l|}{ Distância (m) } \\
\hline $\begin{array}{l}\text { (sem / com } \\
\text { suporte) }\end{array}$ & $1 / 0,81$ & $1 / 0,81$ & $1 / 0,81$ & $0,90 / 0,71$ \\
\hline $\begin{array}{l}\text { Tamanho de } \\
\text { Campo }\left(\mathrm{cm}^{2}\right)\end{array}$ & $10,20,30$ & $10,20,30$ & $10,20,30$ & $10,20,30$ \\
\hline Corrente $(\mathrm{mA})$ & 200 & \multirow{2}{*}{$20 \mathrm{mAs}^{*}$} & 50 & 100 \\
\hline Tempo (s) & 0,1 & & 0,08 & 0,225 \\
\hline \multicolumn{5}{|c|}{$\begin{array}{l}\text { * O equipamento do CEDRUL não possuía a opção de seleção para corrente e tempo, apenas para } \\
\text { produto dessas grandezas. }\end{array}$} \\
\hline \multicolumn{5}{|c|}{$\begin{array}{l}\text { Em todos os laboratórios onde foram realizados testes com o PDC e com o } \\
\text { DAP juntos, o método de calibração utilizado foi o método tandem, descrito por } \\
\text { TOROI et al (5), na seção 2.4.4. A FIG. } 19 \text { ilustra o método tandem e a forma como } \\
\text { essas calibrações foram realizadas. }\end{array}$} \\
\hline
\end{tabular}




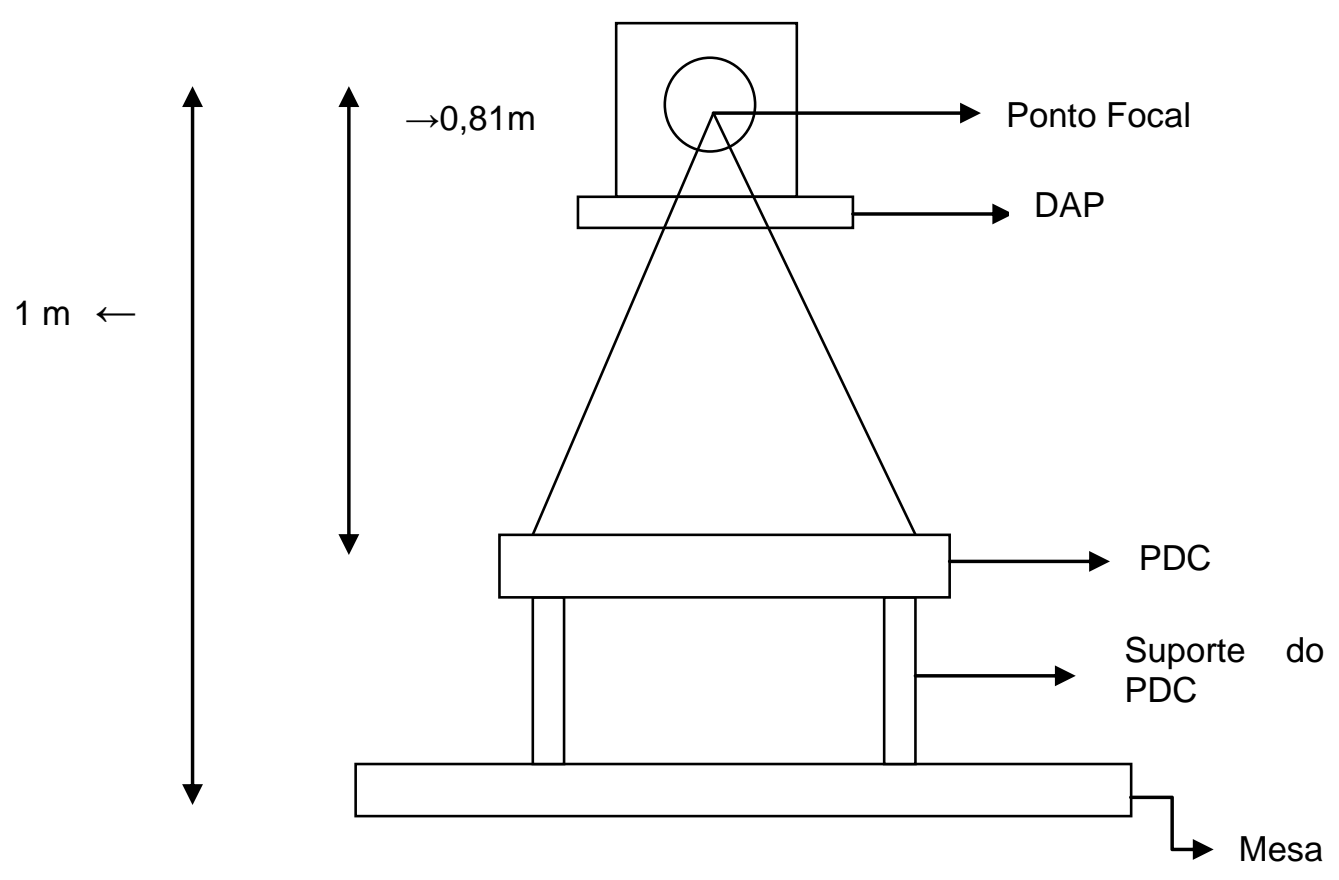

Figura 19. llustração do arranjo de calibração do DAP com o PDC

\subsubsection{Testes realizados na UNIFESP - São Paulo-SP}

Os testes foram realizados com o PDC posicionado sobre a mesa e foram feitas cinco irradiações para as tensões de $50 \mathrm{kV}, 70 \mathrm{kV}, 100 \mathrm{kV}$ e $120 \mathrm{kV}$. Foram utilizados três tamanhos de campo de $10 \mathrm{~cm}, 20 \mathrm{~cm}$ e $30 \mathrm{~cm}$. A corrente utilizada foi de $200 \mathrm{~mA}$, o tempo de $0,1 \mathrm{~s}$ (20 mAs) e foram utilizadas duas distâncias: $1 \mathrm{~m}$ e 0,81 m, sendo o último para os testes com a utilização do suporte do PDC.

Então, o DAP pertencente à UNIFESP foi posicionado na saída do feixe de radiação $\mathrm{X}$ e o PDC posicionado exatamente abaixo, sobre a mesa, e foram feitas irradiações com as mesmas características anteriores, ou seja, nesta etapa o método tandem foi realizado.

\subsubsection{Calibração de um medidor do PKA acoplado a um sistema intervencionista}

A UNIFESP possui um hospital-escola, o Hospital São Paulo. O controle de qualidade dos equipamentos radiológicos presentes no setor de cardiologia 
intervencionista desse hospital é realizado pela Coordenadoria de Física e Higiene das Radiações (CFHR), do Departamento de Diagnóstico por Imagem (DDI) da UNIFESP. Em parceria com o CFHR, a calibração de um medidor do PKA acoplado num sistema intervencionista do hospital foi realizada. A FIG. 20 ilustra o método.

Os seguintes parâmetros foram utilizados:

- Distância fonte-PDC: $80 \mathrm{~cm}$

- Distância detector-fonte: $100 \mathrm{~cm}$

- PDC posicionado sobre a mesa no suporte.

- Modos de magnificação de $15 \mathrm{~cm}, 20 \mathrm{~cm}$ e $25 \mathrm{~cm}$.

- Modos de fluoroscopia low, normal e high.

- Aquisição da imagem em 15 frames por segundo

- Tempo de $30 \mathrm{~s}$.

- Filtro de Cobre de $1 \mathrm{~mm}$ e $2 \mathrm{~mm}$ para proteção do detector.

- Tensões entre $62 \mathrm{kV}$ e $80 \mathrm{kV}$.

- Correntes entre 3,8 mA e 7,1 mA (a tensão e a corrente são ajustadas automaticamente pelo equipamento).

Os modos de fluoroscopia determinam as taxas de dose proporcionadas pelo feixe de raios $\mathrm{X}$. Assim, para um mesmo tempo de exposição, o modo high deverá fornecer uma dose maior ao paciente do que os modos normal e low. Os modos de magnificação permitem ampliação da imagem da região que se quer investigar. É importante destacar que quanto menor o modo de magnificação maior será a dose ministrada, para possibilitar a obtenção da mesma qualidade de imagem ${ }^{22}$. 


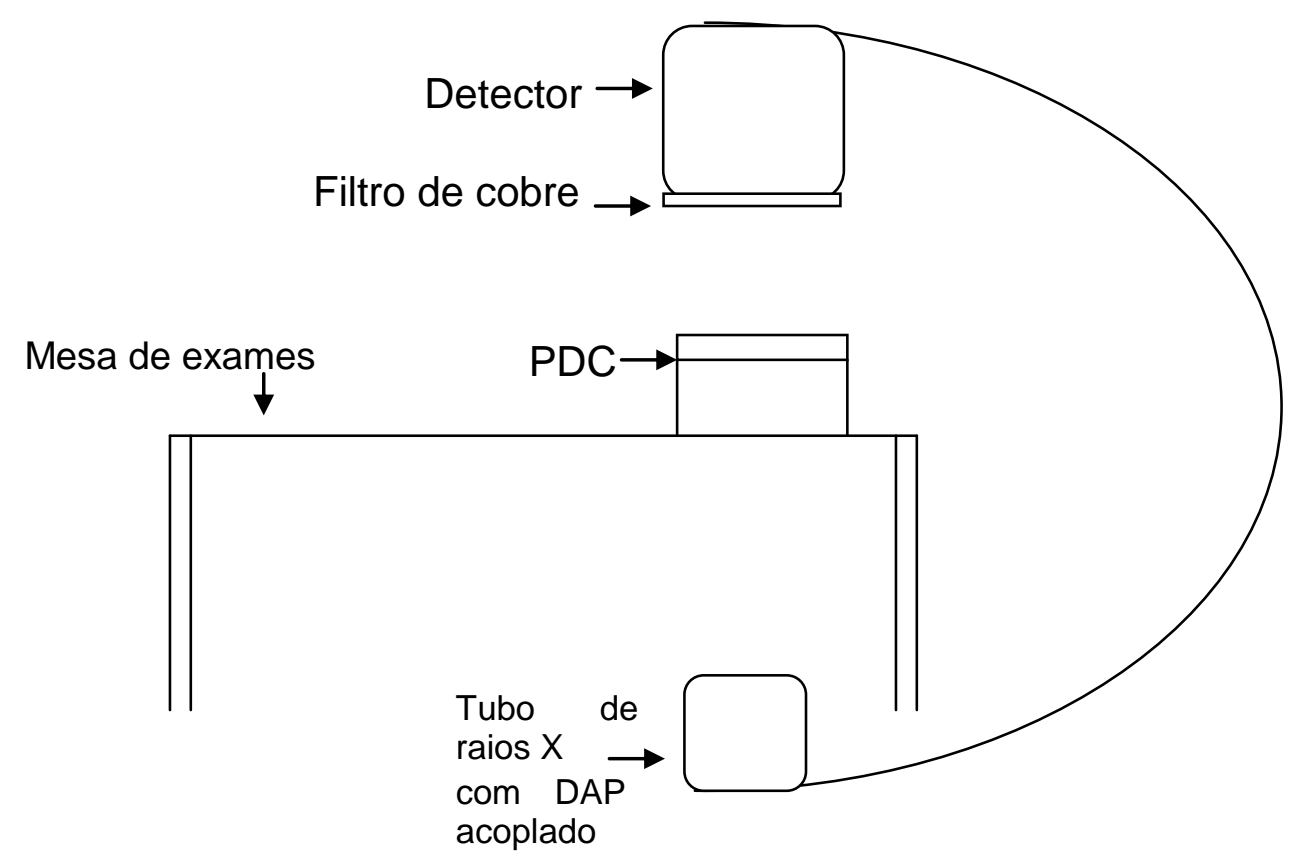

Figura 20. Ilustração do arranjo de calibração de um DAP que é acoplado a um sistema intervencionista

\subsubsection{Testes realizados no CEDRUL - João Pessoa-PB}

Os testes foram realizados similarmente aos testes da UNIFESP. Mesmas tensões, tamanhos de campo e distâncias. $O$ produto corrente $\mathrm{x}$ tempo foi de 20 mAs. Após os testes com o PDC, o DAP pertencente ao IFBA foi posicionado na saída do feixe de radiação $X$ e o PDC posicionado exatamente abaixo, também sobre a mesa, e foram feitas irradiações com todas as características para calibração pelo método tandem.

\subsubsection{Testes realizados no DEN - Recife-PE}

\subsubsection{Medições nas qualidades implantadas no sistema de radiação $X$}

Quanto aos testes realizados no DEN, foram utilizados dois tipos de equipamentos de radiação $X$ no laboratório. Um dos equipamentos é industrial e possui quatro qualidades de radiação diagnóstica implantadas: RQR 5 (70 kV), RQR 7 (90 kV), RQR 8 (100 kV) e RQR 10 (150 kV). Para tomografia computadorizada são três qualidades implantadas: RQT 8 (100 kV), RQT 9 (120 kV) e RQT 10 (150 kV). Já para mamografia são duas: WMV 28 (28 kV) e 
WMV 35 (35 kV). Neste equipamento, foram realizadas medições em todas as qualidades implantadas. O PDC foi posicionado a $1 \mathrm{~m}$ do ponto focal, com o feixe central direcionado para o centro do PDC. A corrente utilizada foi de $10 \mathrm{~mA}$, com cinco irradiações de $30 \mathrm{~s}$ para cada qualidade.

\subsubsection{Calibração do DAP}

$O$ outro equipamento de radiação $X$ no DEN é um equipamento diagnóstico e as medições foram realizadas nas seguintes tensões: $50 \mathrm{kV}, 70 \mathrm{kV}$ e $90 \mathrm{kV}$. A corrente utilizada foi de $50 \mathrm{~mA}$ e o tempo de $0,08 \mathrm{~s}$ (4 mAs). Devido às limitações do equipamento, parâmetros como tensão, corrente e tempos maiores não puderam ser utilizados. Os primeiros testes foram realizados com o PDC posicionado sobre a mesa a $1 \mathrm{~m}$ de distância do ponto focal e com o PDC no suporte, a 0,81 m do ponto focal, sendo cinco irradiações para cada tensão.

Foram realizadas medições com o PDC posicionado no suporte, como mostra a FIG. 21 e com o DAP pertencente ao DEN posicionado na saída do feixe de radiação para os três tamanhos de campo e para as três tensões escolhidas, conforme o método tandem.

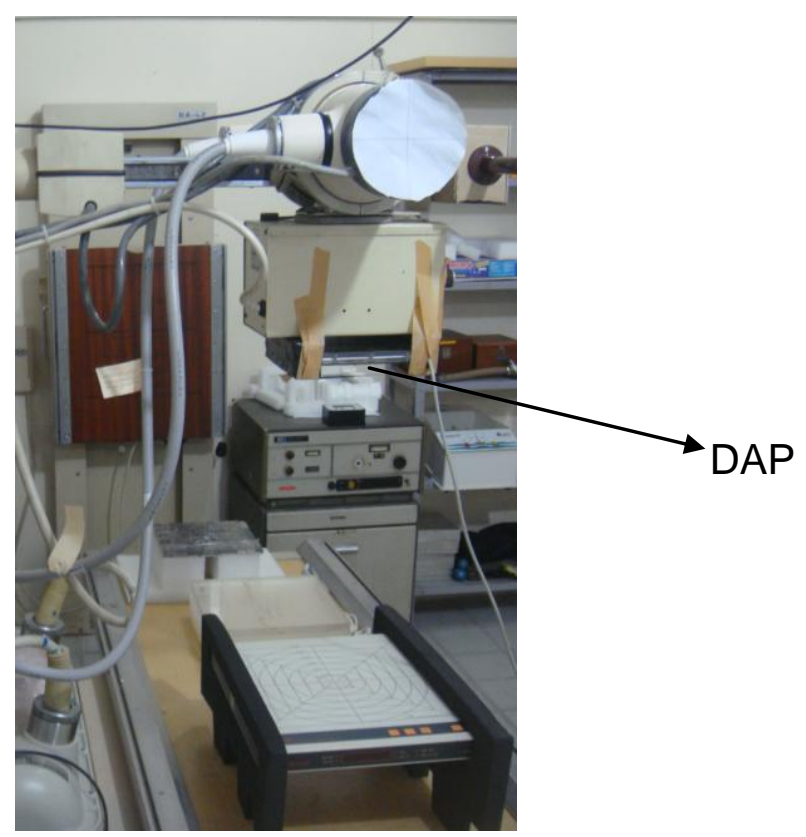

Figura 21. Calibração do DAP do DEN. DAP posicionado na saída do feixe de radiação X e o PDC posicionado abaixo, no suporte. 
O tamanho do campo correspondente a $10 \mathrm{~cm}^{2}$ foi confirmado através de uma radiografia. A FIG. 22 mostra a radiografia do tamanho de campo.

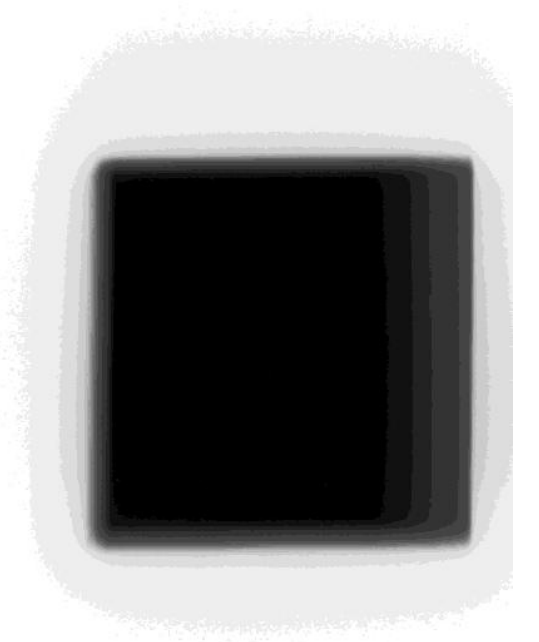

Figura 22. Campo de $10 \mathrm{~cm} \times 10 \mathrm{~cm}$ radiografado para confirmação de tamanho no DEN

\subsubsection{Testes realizados no IFBA}

Os testes foram realizados com os seguintes parâmetros: tensões de $50 \mathrm{kV}$, 70 kV e 90 kV; corrente de 100 mA; distâncias de 0,90 m com o PDC posicionado sobre a mesa e de 0,71 m com o PDC no suporte; tamanhos de campo de $10 \mathrm{~cm}, 20$ cm e $30 \mathrm{~cm}$; cinco irradiações para cada tensão; tempo variável, pois o equipamento não possui o tempo como ajuste fixo. $O$ mesmo depende do intervalo onde o operador pressiona o botão para irradiação. Entretanto, o tempo médio foi de 0,2 s.

Os primeiros testes foram realizados com o PDC posicionado sobre a mesa para cada tensão e tamanho de campo. Na sequência, medições foram realizadas com o PDC posicionado no suporte. Então, o DAP pertencente ao IFBA foi posicionado na saída do feixe de radiação e foram realizadas medições com ambos, estando o PDC sobre a mesa e no suporte, seguindo o método tandem. A radiografia para confirmação do tamanho de campo também foi realizada, como visto na FIG. 23. 


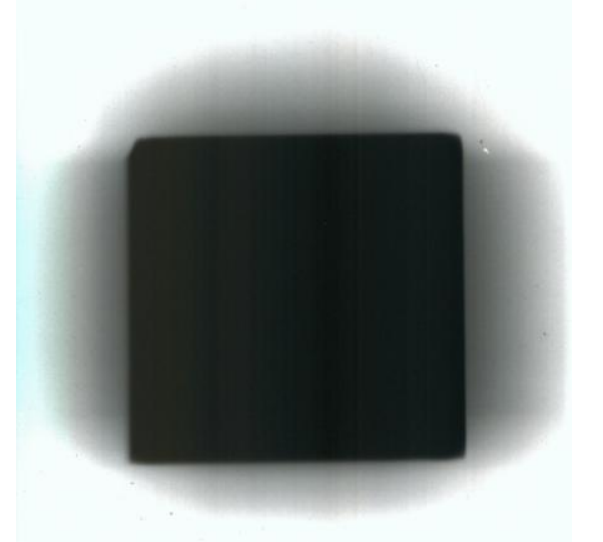

Figura 23. Campo de $10 \mathrm{~cm} \times 10 \mathrm{~cm}$ radiografado para confirmação de tamanho no IFBA

\subsubsection{Análise de Incertezas}

Para a estimativa das incertezas apresentadas nas medições realizadas em laboratório foram utilizadas as recomendações do Guia Para a Expressão da Incerteza de Medição (23) e foram consideradas as incertezas do tipos A e B, para um nível de confiança de $95 \%(\mathrm{k}=2)$.

Para estimar a incerteza do tipo A para cada medição foi calculado o desvio padrão e o desvio padrão da média. Para se obter o desvio padrão $u_{i}$ de uma série de medições realizadas utiliza-se a equação 10 .

$$
u_{i}=\sqrt{\frac{1}{n-1} \sum_{i=1}^{n}\left(y_{i}-\bar{y}\right)^{2}}
$$

No qual,

$n$ é o número de medições realizadas

$y_{i}$ é o valor medido

$\bar{y}$ é a média desses valores.

O desvio padrão caracteriza a dispersão dos valores $y_{i}$ em torno de sua média $\bar{y}$. Já o desvio padrão da média quantifica quão bem $\bar{y}$ estima a esperança $\mu_{y}$ de $y$, ou seja, ele nos mostra o quão distante a média das medições realizadas está do 
valor esperado, e é obtido dividindo-se o desvio padrão, calculado na equação 10 , por $\sqrt{n}$ (raiz quadrada do número de medições realizadas).

Por outro lado, a incerteza do tipo B é um método de avaliação da incerteza por outros meios que não a análise estatística. Ela é avaliada por julgamento científico, baseando-se em todas as informações disponíveis sobre a possível variabilidade de $X_{i}$ (grandeza de entrada qualquer). $O$ conjunto de informações pode incluir especificações do fabricante, dados fornecidos em certificados de calibração e outros certificados.

Para a incerteza do tipo B foi considerado a repetibilidade, incerteza e resolução do termômetro, influência da temperatura ambiente, incerteza e resolução do barômetro, influência da pressão do ambiente, incerteza do posicionamento do padrão e a resolução do sistema de medida. 


\section{$4 \quad$ RESULTADOS E DISCUSSÕES}

\subsection{Avaliação de desempenho do PDC de acordo com as normas IEC 61674 e IEC 60580}

A TAB. 5 mostra os testes de caracterização a que o PDC foi submetido antes de ser utilizado como equipamento de referência para calibração de medidores do PKA.

Tabela 5. Características de desempenho, limites estabelecidos pelas normas IEC 61674 e IEC 60580 e resultados obtidos pelo PDC.

\begin{tabular}{|c|c|c|c|c|c|}
\hline \multicolumn{6}{|c|}{ IEC 61674 e IEC 60580} \\
\hline Características & $\begin{array}{l}\text { Qualidades de } \\
\text { radiação }\end{array}$ & \multicolumn{2}{|c|}{ Limites (\%) } & \multicolumn{2}{|c|}{$\begin{array}{c}\text { Valores Obtidos } \\
\text { (\%) }\end{array}$} \\
\hline & RQR3 & \multicolumn{2}{|c|}{8,25} & \multicolumn{2}{|c|}{6,02} \\
\hline & RQR5 & \multicolumn{2}{|c|}{6,95} & \multicolumn{2}{|c|}{4,1} \\
\hline Erro Intríseco Relativo & RQR8 & \multicolumn{2}{|c|}{ \pm 5} & \multicolumn{2}{|c|}{1,5} \\
\hline & RQR10 & \multicolumn{2}{|c|}{ \pm 5} & \multicolumn{2}{|c|}{1,87} \\
\hline & & Taxa & Acum & Taxa & Acum \\
\hline & RQR3 & 4,83 & 2,6 & 2,13 & 2,25 \\
\hline Repetibilidade & RQR5 & 4,52 & 2,56 & 1,85 & 2,09 \\
\hline & RQR8 & 3,95 & 2,47 & 3,01 & 2,4 \\
\hline & RQR10 & 3 & 2,32 & 2,36 & 1.34 \\
\hline & RQR3 & \multirow{4}{*}{\multicolumn{2}{|c|}{$\leq 1$}} & \multicolumn{2}{|c|}{0,12} \\
\hline Resolução de Leitura & RQR5 & & & \multicolumn{2}{|c|}{0,05} \\
\hline & RQR8 & & & \multicolumn{2}{|c|}{0,44} \\
\hline & RQR10 & & & \multicolumn{2}{|c|}{0,64} \\
\hline Tempo de Estabilização & Todos & \multicolumn{2}{|c|}{ \pm 2} & \multicolumn{2}{|c|}{ Todos 0} \\
\hline Reiniciar & Todos & \multicolumn{2}{|c|}{$\leq 1$} & \multicolumn{2}{|c|}{ Todos 0} \\
\hline $\begin{array}{l}\text { Efeitos de Fuga de } \\
\text { Corrente }\end{array}$ & Todos & \multicolumn{2}{|c|}{$\leq 5$} & \multicolumn{2}{|c|}{ Todos 0} \\
\hline \multicolumn{6}{|c|}{ IEC 60580} \\
\hline $\begin{array}{l}\text { Desvio de valores } \\
\text { indicados }\end{array}$ & Todos & \multicolumn{2}{|c|}{$\begin{array}{c}\text { Menor do que } 10 \% \\
\text { por pelo menos } 1 \\
\text { hora }\end{array}$} & \multicolumn{2}{|c|}{$\begin{array}{c}\text { Sem alteração de } \\
\text { valores }\end{array}$} \\
\hline Tempo de Resposta & Todos & \multicolumn{2}{|c|}{$\begin{array}{l}90 \% \text { do valor final } \\
\text { dentro de } 3 \\
\text { segundos }\end{array}$} & \multicolumn{2}{|c|}{$\begin{array}{l}\text { Menor do que } 2 \\
\text { segundos }\end{array}$} \\
\hline $\begin{array}{c}\text { Uniformidade Espacial de } \\
\text { Resposta }\end{array}$ & Todos & \multicolumn{2}{|c|}{ $\pm 5 \%$} & \multicolumn{2}{|c|}{0} \\
\hline
\end{tabular}

Os resultados mostraram que o PDC está dentro dos padrões de qualidade e que possui bom funcionamento nos testes de desempenho para equipamentos caracterizados como dosímetros com câmaras de ionização, segundo a norma IEC $61674^{21}$, mesmo embora a norma não cite equipamentos como o PDC. 
Para a norma IEC $60580^{7}$, que é específica para medidores do PKA, o PDC também mostrou excelente funcionalidade por estar dentro de todos os limites estabelecidos.

\subsection{Calibração do PDC segundo o código de prática TRS $457^{1}$}

Conforme descrito na seção 2.4.1 e na figura 9, a calibração foi realizada com o PDC nas posições I e II. Com o PDC na posição I, porém, houve uma considerável atenuação do feixe, de aproximadamente 30\%. Essa alta atenuação do feixe prova que o PDC é um equipamento para ser utilizado como referência para calibração de medidores do PKA, mas não é adequado para uso clínico, pois a recomendação para este fim é que a atenuação não seja maior do que $20 \%$.

Os valores dos fatores de correção para as qualidades e o coeficiente de calibração do PDC são mostrados na tabela 6.

Tabela 6. Coeficiente de Calibração e fatores de correção do PDC.

\begin{tabular}{cccc} 
N PKA: $\mathbf{1 , 0 1 8} \mathbf{0} \mathbf{0 , 0 0 7}$ Gy.m²/u.e. & & \\
\hline $\begin{array}{c}\text { Qualidades de } \\
\text { Radiação }\end{array}$ & Tensão (kV) & $\begin{array}{c}\text { Camada } \\
\text { Semirredutora } \\
(\mathrm{mmAl})\end{array}$ & $\begin{array}{c}\text { Fator de } \\
\text { Correção } \\
\mathrm{K}_{\mathrm{Q}}\end{array}$ \\
\hline RQR 3 & 50 & 1,78 & 1,03 \\
RQR 5 & 70 & 2,58 & 1 \\
RQR 8 & 100 & 3,97 & 0,97 \\
RQR 10 & 150 & 6,57 & 0,94 \\
\hline
\end{tabular}

u.e.: unidade da escala

A calibração em feixes padrões de radiação permite a determinação de um procedimento especial de calibração de medidores do PKA e mostra que ele pode ser usado como instrumento de referência para calibração de outros medidores do PKA. 


\subsection{Avaliação da dependência energética}

A avaliação da dependência energética do PDC foi necessária principalmente pelo fato de que estudos anteriores apresentavam o PDC como equipamento com dependência energética menor do que outros equipamentos medidores do $\mathrm{PKA}^{9}$. Este estudo foi realizado a partir da calibração do PDC para as qualidades de radiodiagnóstico. A dependência energética foi encontrada a partir dos valores de camada semirredutora, mostrados na TAB. 3, e dos fatores de correção do PDC, mostrados na TAB. 6.

A FIG. 24 mostra o gráfico de dependência energética do PDC e a equação de ajuste encontrada para que se possa descobrir o fator de correção para qualidades de radiação diferentes das estabelecidas pelo $\mathrm{LCl}$, através da interpolação de valores. O maior valor de dependência energética encontrado foi de $6 \%$.

A norma IEC 60580 permite uma incerteza padrão combinada de $25 \%(k=2)$ para medidas de PKA sob condições específicas. Para a dependência energética, a norma permite um desvio de $8 \%$ do valor de referência quando a filtração total é de 2,5 mm de alumínio e a tensão do tubo de radiação X está entre $50 \mathrm{kV}$ e $150 \mathrm{kV}$.

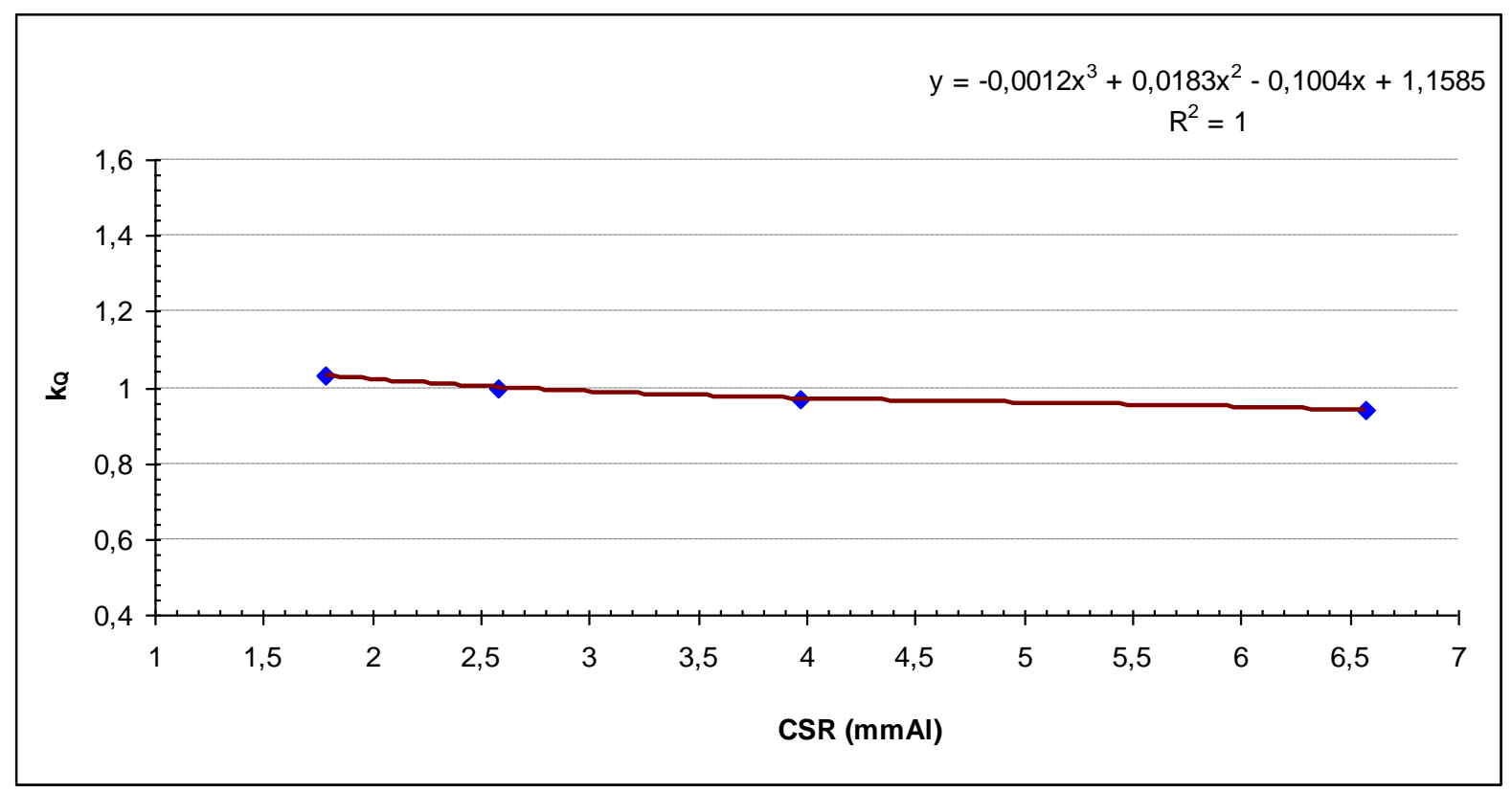

Figura 24. Dependência energética do PDC para as qualidades de radiodiagnóstico implantadas no LCl 


\subsection{Uso do PDC em equipamentos de mamografia}

Um estudo sobre a avaliação do PDC para medidas do PKA em qualidade de radiação em mamografia foi realizado. Neste estudo, valores de kerma no ar foram obtidos para as qualidades WMV's e WMH's. As tensões avaliadas foram de $25 \mathrm{kV}$, $28 \mathrm{kV}, 30 \mathrm{kV}$ e $35 \mathrm{kV}$. O manual do PDC mostra que ele deve ser utilizado entre $40 \mathrm{kV}$ e $150 \mathrm{kV}$. Entretanto, as medições indicam que o PDC está apto a realizar medições abaixo de $40 \mathrm{kV}$, desde que o coeficiente de calibração seja aplicado. As TAB. 7 e 8 mostram os valores obtidos com a leitura.

Tabela 7. Valores obtidos para WMV

\begin{tabular}{cccccc}
\hline $\begin{array}{c}\text { Qualidades } \\
\text { de }\end{array}$ & $\begin{array}{c}\text { Tensão } \\
\text { Radiação }\end{array}$ & $\begin{array}{c}\text { PDV } \\
(\mathbf{m G y} / \mathbf{m i n})\end{array}$ & $\begin{array}{c}\text { PDC }^{*} \\
(\mathbf{m G y})\end{array}$ & $\begin{array}{c}\text { Taxa de } \\
\text { kerma no } \\
\text { ar } \\
\text { Referência } \\
\text { (mGy/min) }\end{array}$ & $\begin{array}{c}\text { Coeficiente } \\
\text { de } \\
\text { Calibração } \\
\left(\mathbf{N}_{\mathbf{k}}\right)\end{array}$ \\
\hline WMV 25 & 25 & $6,71 \pm 0,15$ & $6,73 \pm 0,13$ & 9,78 & 1,45 \\
WMV 28 & 28 & $8,52 \pm 0,17$ & $8,51 \pm 0,17$ & 12,20 & 1,43 \\
WMV 30 & 30 & $9,76 \pm 0,19$ & $9,72 \pm 0,19$ & 13,83 & 1,42 \\
WMV 35 & 35 & $12,93 \pm 0,25$ & $12,9 \pm 0,25$ & 17,97 & 1,39 \\
\hline
\end{tabular}

*medições realizadas em 1 min

Tabela 8. Valores obtidos para WMH

\begin{tabular}{|c|c|c|c|c|c|}
\hline $\begin{array}{c}\text { Qualidades } \\
\text { de } \\
\text { Radiação }\end{array}$ & $\begin{array}{c}\text { Tensão } \\
(\mathbf{k V})\end{array}$ & $\begin{array}{c}\text { PDC } \\
\text { (mGy/min) }\end{array}$ & $\begin{array}{l}\text { PDC* }^{*} \\
\text { (mGy) }\end{array}$ & $\begin{array}{c}\text { Taxa de } \\
\text { kerma no } \\
\text { ar } \\
\text { Referência } \\
\text { (mGy/min) }\end{array}$ & $\begin{array}{c}\text { Coeficiente } \\
\text { de } \\
\text { Calibração } \\
\left(\mathrm{N}_{\mathrm{k}}\right)\end{array}$ \\
\hline WMH 25 & 25 & $0,35 \pm 0,07$ & $0,36 \pm 0,07$ & 0,470 & 1,34 \\
\hline WMH 28 & 28 & $0,54 \pm 0,01$ & $0,54 \pm 0,01$ & 0,671 & 1,34 \\
\hline WMH 30 & 30 & $0,721 \pm 0,014$ & $0,71 \pm 0,01$ & 0,845 & 1,20 \\
\hline WMH 35 & 35 & $1,347 \pm 0,026$ & $1,31 \pm 0,02$ & 1,47 & 1,13 \\
\hline
\end{tabular}

${ }^{*}$ medições realizadas em 1 min 


\subsection{Calibração de medidores do PKA utilizando o PDC como referência}

Com a realização de todos os testes de desempenho, caracterização e funcionamento do PDC, foi realizada a aplicação de metodologia de calibração de medidores do PKA usando o PDC como referência. O método utilizado foi o método tandem, como descrito na seção 2.4.4. Todas as medidas foram realizadas in situ em equipamentos clínicos e foram corrigidas para as condições ambientais. Os valores obtidos pelo PDC foram corrigidos de acordo com a equação 9. Os coeficientes de calibração foram encontrados utilizando-se a equação 8 , apenas para a grandeza PKA que é o foco deste estudo.

A TAB. 9 mostra os resultados das medições para a calibração in situ do instrumento da UNIFESP, conforme descrito no item 3.3.1. Os coeficientes de calibração encontrados, mostrados na TAB. 10, demonstraram uma variação de $16 \%$ para um campo de $10 \times 10 \mathrm{~cm}$.

Tabela 9. Valores de PKA e Kerma no ar obtidos na UNIFESP - São Paulo

\begin{tabular}{|c|c|c|c|c|c|c|}
\hline $\begin{array}{c}\text { Tensão } \\
\text { (kV) }\end{array}$ & $\begin{array}{l}\text { Campo } \\
10 \mathrm{~cm}\end{array}$ & $\begin{array}{l}\text { Campo } \\
20 \mathrm{~cm}\end{array}$ & $\begin{array}{l}\text { Campo } \\
30 \mathrm{~cm}\end{array}$ & $\begin{array}{c}\text { Suporte } \\
10 \mathrm{~cm}\end{array}$ & $\begin{array}{l}\text { Suporte } \\
20 \mathrm{~cm}\end{array}$ & $\begin{array}{l}\text { Suporte } \\
30 \mathrm{~cm}\end{array}$ \\
\hline \multicolumn{7}{|c|}{ PDC PKA ( $\mu$ Gy.m²) } \\
\hline 50 & $3,423 \pm 0,002$ & $14,11 \pm 0,09$ & $31,04 \pm 0,01$ & $13,813 \pm 0,002$ & $13,817 \pm 0,003$ & $29,962 \pm 0,001$ \\
\hline 70 & $7,81 \pm 0,02$ & $31,46 \pm 0,01$ & $74,3 \pm 0,1$ & $30,546 \pm 0,005$ & $30,54 \pm 0,01$ & $71,6 \pm 0,1$ \\
\hline 100 & $16,52 \pm 0,01$ & $68,2 \pm 0,1$ & $155,15 \pm 0,08$ & $66,17 \pm 0,02$ & $66,2 \pm 0,1$ & $148,37 \pm 0,09$ \\
\hline 120 & $22,52 \pm 0,01$ & $93,67 \pm 0,07$ & $214,4 \pm 0,2$ & $20,33 \pm 0,01$ & $92,93 \pm 0,08$ & $201,9 \pm 0,1$ \\
\hline \multicolumn{7}{|c|}{ PDC Taxa do PKA ( $\mu$ Gy.m²/min) } \\
\hline 50 & $203,04 \pm 0,17$ & $834,82 \pm 0,58$ & $1036,69 \pm 1,02$ & $186,61 \pm 0,24$ & $817,4 \pm 0,2$ & $1771,44 \pm 0,71$ \\
\hline 70 & $471,2 \pm 0,2$ & $1897,43 \pm 1,12$ & $4492,62 \pm 4,86$ & $417,2 \pm 0,2$ & $1841,44 \pm 0,67$ & $4316,21 \pm 6,43$ \\
\hline 100 & $1007,82 \pm 0,86$ & $4160,88 \pm 4,45$ & $9464,05 \pm 4,26$ & $889,63 \pm 0,67$ & $4037,42 \pm 8,03$ & $9052,66 \pm 4,53$ \\
\hline 120 & $1380,6 \pm 1,61$ & $5745,04 \pm 4,33$ & $13156,03 \pm 15,38$ & $1247,07 \pm 0,94$ & $5699,81 \pm 5,19$ & $12381,86 \pm 9,98$ \\
\hline
\end{tabular}




\begin{tabular}{|c|c|c|c|c|c|c|}
\hline $\begin{array}{c}\text { Tensão } \\
\text { (kV) }\end{array}$ & $\begin{array}{c}\text { Campo } \\
10 \mathrm{~cm}\end{array}$ & $\begin{array}{c}\text { Campo } \\
20 \mathrm{~cm}\end{array}$ & $\begin{array}{c}\text { Campo } \\
30 \mathrm{~cm}\end{array}$ & $\begin{array}{c}\text { Suporte } \\
10 \mathrm{~cm}\end{array}$ & $\begin{array}{l}\text { Suporte } \\
20 \mathrm{~cm}\end{array}$ & $\begin{array}{l}\text { Suporte } \\
30 \mathrm{~cm}\end{array}$ \\
\hline \multicolumn{7}{|c|}{ PDC Kerma ( $\mu \mathrm{Gy})$} \\
\hline 50 & $0,3301 \pm 0,0003$ & $0,3892 \pm 0,0005$ & $0,4021 \pm 0,0003$ & $0,3241 \pm 0,0005$ & $0,3794 \pm 0,0004$ & $0,3849 \pm 0,0003$ \\
\hline 70 & $0,7625 \pm 0,0008$ & $0,8805 \pm 0,0006$ & $0,9397 \pm 0,0003$ & $0,7405 \pm 0,0009$ & $0,8473 \pm 0,0003$ & $0,8942 \pm 0,0002$ \\
\hline 100 & $1,586 \pm 0,002$ & $1,848 \pm 0,001$ & $1,965 \pm 0,001$ & $1,532 \pm 0,001$ & $1,772 \pm 0,001$ & $1,835 \pm 0,001$ \\
\hline 120 & $2,184 \pm 0,002$ & $2,533 \pm 0,003$ & $2,694 \pm 0,002$ & $2,127 \pm 0,001$ & $2,436 \pm 0,001$ & $2,5441 \pm 0,0006$ \\
\hline \multicolumn{7}{|c|}{ DAP PKA $\left(\mu G y \cdot m^{2}\right)$} \\
\hline 50 & $3,698 \pm 0,005$ & $13,36 \pm 0,01$ & $29,492 \pm 0,006$ & * & * & * \\
\hline 70 & $9,23 \pm 0,01$ & $33,34 \pm 0,01$ & $74,07 \pm 0,23$ & * & * & * \\
\hline 100 & $19,07 \pm 0,01$ & $68,90 \pm 0,02$ & $152,009 \pm 0,007$ & * & * & * \\
\hline 120 & $25,60 \pm 0,01$ & $92,26 \pm 0,02$ & $203,55 \pm 0,18$ & * & * & * \\
\hline
\end{tabular}

*Valores não obtidos pois o DAP permitia leitura somente do produto kerma-área.

Tabela 10. Valores de Coeficiente de Calibração $\left(N_{K}\right)$ obtidos para o DAP da UNIFESP.

\begin{tabular}{ccccccc}
\hline $\begin{array}{c}\text { Tensão } \\
\mathbf{( k V )}\end{array}$ & $\begin{array}{c}\text { Campo } \\
\mathbf{1 0} \mathbf{~ c m}\end{array}$ & $\begin{array}{c}\text { Campo } \\
\mathbf{2 0} \mathbf{~ c m}\end{array}$ & $\begin{array}{c}\text { Campo } \\
\mathbf{3 0} \mathbf{~ c m}\end{array}$ & $\begin{array}{c}\text { Suporte } \\
\mathbf{1 0} \mathbf{~ c m}\end{array}$ & $\begin{array}{c}\text { Suporte } \\
\mathbf{2 0} \mathbf{~ c m}\end{array}$ & $\begin{array}{c}\text { Suporte } \\
\mathbf{3 0} \mathbf{~ c m}\end{array}$ \\
\hline $\mathbf{5 0}$ & 0,92 & 1,05 & 1,05 & $*$ & $*$ & $*$ \\
$\mathbf{7 0}$ & 0,84 & 0,94 & 1,00 & $*$ & $*$ & $*$ \\
$\mathbf{1 0 0}$ & 0,86 & 0,98 & 1,02 & $*$ & $*$ & $*$ \\
$\mathbf{1 2 0}$ & 0,87 & 1,01 & 1,05 & $*$ & $*$ & $*$
\end{tabular}


A TAB. 11 mostra os resultados das medições para a calibração in situ do instrumento do IFBA, utilizado no CEDRUL, conforme descrito no item 3.3.2. Os coeficientes de calibração encontrados, mostrados na TAB. 12, demonstraram uma variação de $34 \%$ para um campo de $10 \times 10 \mathrm{~cm}$.

Tabela 11. Valores de PKA e Kerma no ar obtidos no CEDRUL - João Pessoa

\begin{tabular}{|c|c|c|c|c|c|c|}
\hline $\begin{array}{c}\text { Tensão } \\
(\mathrm{kV})\end{array}$ & $\begin{array}{c}\text { Campo } \\
10 \mathrm{~cm}\end{array}$ & $\begin{array}{l}\text { Campo } \\
20 \mathrm{~cm}\end{array}$ & $\begin{array}{c}\text { Campo } \\
30 \mathrm{~cm}\end{array}$ & $\begin{array}{l}\text { Suporte } \\
10 \mathrm{~cm}\end{array}$ & $\begin{array}{l}\text { Suporte } \\
20 \mathrm{~cm}\end{array}$ & $\begin{array}{c}\text { Suporte } \\
30 \mathrm{~cm}\end{array}$ \\
\hline \multicolumn{7}{|c|}{ PDC PKA ( $\mu$ Gy.m²) } \\
\hline 50 & $2,22 \pm 0,05$ & $9,67 \pm 0,07$ & * & $2,72 \pm 0,02$ & $8,73 \pm 0,14$ & * \\
\hline 70 & $5,07 \pm 0,03$ & * & $48,1 \pm 0,4$ & $4,49 \pm 0,01$ & * & $43,51 \pm 0,91$ \\
\hline 100 & $13,07 \pm 0,17$ & $55,4 \pm 1,5$ & $119,2 \pm 1,0$ & $10,69 \pm 0,08$ & $44,76 \pm 0,58$ & $103,6 \pm 1,2$ \\
\hline 120 & $17,13 \pm 0,18$ & $72,5 \pm 1,6$ & $157,06 \pm 3,46$ & $13,73 \pm 0,35$ & $60,01 \pm 0,41$ & $134,7 \pm 0,4$ \\
\hline \multicolumn{7}{|c|}{ PDC Taxa do PKA ( $\mu$ Gy.m $\left.\mathrm{m}^{2} / \mathrm{min}\right)$} \\
\hline 50 & $131,6 \pm 2,9$ & $584,6 \pm 5,2$ & * & $163,6 \pm 1,6$ & $523,4 \pm 8,4$ & * \\
\hline 70 & $303,2 \pm 1,6$ & * & $2881,8 \pm 25,8$ & $269,6 \pm 1,1$ & * & $2608,3 \pm 54,9$ \\
\hline 100 & $783,1 \pm 9,1$ & $3321,2 \pm 50,4$ & $7115,6 \pm 62,4$ & $628,04 \pm 8,08$ & $2683,4 \pm 34,7$ & $6209,5 \pm 71,9$ \\
\hline 120 & $1027 \pm 11$ & $4338,6 \pm 94,6$ & $9545,4 \pm 76,1$ & $823,2 \pm 21,5$ & $3602,6 \pm 24,2$ & $8074,2 \pm 29,7$ \\
\hline \multicolumn{7}{|c|}{ PDC Kerma ( $\mu$ Gy) } \\
\hline 50 & $0,191 \pm 0,004$ & $0,250 \pm 0,002$ & * & $0,255 \pm 0,002$ & $0,228 \pm 0,003$ & * \\
\hline 70 & $0,324 \pm 0,003$ & * & $0,562 \pm 0,005$ & $0,417 \pm 0,001$ & * & $0,50 \pm 0,01$ \\
\hline 100 & $1,124 \pm 0,015$ & $1,33 \pm 0,03$ & $1,41 \pm 0,01$ & $0,973 \pm 0,008$ & $1,071 \pm 0,014$ & $1,19 \pm 0,01$ \\
\hline 120 & $1,47 \pm 0,02$ & $1,746 \pm 0,003$ & $1,863 \pm 0,041$ & $1,26 \pm 0,03$ & $1,452 \pm 0,011$ & $1,554 \pm 0,003$ \\
\hline
\end{tabular}




\begin{tabular}{|c|c|c|c|c|c|c|}
\hline $\begin{array}{c}\text { Tensão } \\
(k V)\end{array}$ & $\begin{array}{l}\text { Campo } \\
10 \mathrm{~cm}\end{array}$ & $\begin{array}{l}\text { Campo } \\
20 \mathrm{~cm}\end{array}$ & $\begin{array}{c}\text { Campo } \\
30 \mathrm{~cm}\end{array}$ & $\begin{array}{c}\text { Suporte } \\
10 \mathrm{~cm}\end{array}$ & $\begin{array}{c}\text { Suporte } \\
20 \mathrm{~cm}\end{array}$ & $\begin{array}{c}\text { Suporte } \\
30 \mathrm{~cm}\end{array}$ \\
\hline \multicolumn{7}{|c|}{ DAP PKA ( $\mu$ Gy.m²) } \\
\hline 50 & $1,83 \pm 0,02$ & $9,16 \pm 0,06$ & * & $* *$ & ** & ** \\
\hline 70 & $4,22 \pm 0,02$ & * & $45,76 \pm 0,97$ & ** & ** & ** \\
\hline 100 & $9,90 \pm 0,11$ & $46,4 \pm 0,7$ & $106,6 \pm 1,3$ & $\star \star$ & $\star \star$ & $\star *$ \\
\hline 120 & $12,81 \pm 0,16$ & $59,44 \pm 1,44$ & $128,13 \pm 2,01$ & $\star *$ & $\star *$ & $\star *$ \\
\hline \multicolumn{7}{|c|}{ DAP Kerma ( $\mu G y)$} \\
\hline 50 & $0,0217 \pm 0,0002$ & $0,049 \pm 0,003$ & * & ** & ** & ** \\
\hline 70 & $0,0583 \pm 0,0002$ & * & $0,091 \pm 0,003$ & ** & ** & $\star \star *$ \\
\hline 100 & $0,136 \pm 0,001$ & $0,204 \pm 0,002$ & $0,225 \pm 0,002$ & ** & ** & ** \\
\hline 120 & $0,169 \pm 0,001$ & $0,262 \pm 0,007$ & $0,278 \pm 0,002$ & ** & ** & $\star *$ \\
\hline
\end{tabular}

${ }^{\star}$ Erro de leitura do PDC.

** No método tandem, medições realizadas somente com o PDC sobre a mesa.

Tabela 12. Valores de Coeficiente de Calibração $\left(N_{K}\right)$ obtidos para o DAP do IFBA utilizado no

\begin{tabular}{ccccccc}
\hline $\begin{array}{c}\text { Tensão } \\
\mathbf{( k V )}\end{array}$ & $\begin{array}{c}\text { Campo } \\
\mathbf{1 0} \mathbf{~ c m}\end{array}$ & $\begin{array}{c}\text { Campo } \\
\mathbf{2 0} \mathbf{~ c m}\end{array}$ & $\begin{array}{c}\text { Campo } \\
\mathbf{3 0} \mathbf{~ c m}\end{array}$ & $\begin{array}{c}\text { Suporte } \\
\mathbf{1 0} \mathbf{~ c m}\end{array}$ & $\begin{array}{c}\text { Suporte } \\
\mathbf{2 0} \mathbf{~ c m}\end{array}$ & $\begin{array}{c}\text { Suporte } \\
\mathbf{3 0} \mathbf{~ c m}\end{array}$ \\
\hline $\mathbf{5 0}$ & 1,21 & 1,06 & $*$ & $*$ & $*$ & $*$ \\
$\mathbf{7 0}$ & 1,20 & $*$ & 1,05 & $*$ & $*$ & $*$ \\
$\mathbf{1 0 0}$ & 1,32 & 1,19 & 1,12 & $*$ & $*$ & $*$ \\
$\mathbf{1 2 0}$ & 1,34 & 1,22 & 1,23 & $*$ & $*$ & $*$ \\
\hline
\end{tabular}


A TAB. 13 mostra os resultados das medições para a calibração in situ do instrumento do DEN, conforme descrito no item 3.3.3.2. Os coeficientes de calibração encontrados, mostrados na TAB. 14, demonstraram uma variação de $11 \%$ para um campo de $30 \times 30 \mathrm{~cm}$.

Tabela 13. Valores de PKA e Kerma no ar obtidos no DEN - Recife

\begin{tabular}{|c|c|c|c|c|c|c|}
\hline $\begin{array}{c}\text { Tensão } \\
\text { (kV) }\end{array}$ & $\begin{array}{c}\text { Campo } \\
10 \mathrm{~cm}\end{array}$ & $\begin{array}{c}\text { Campo } \\
20 \mathrm{~cm}\end{array}$ & $\begin{array}{l}\text { Campo } \\
30 \mathrm{~cm}\end{array}$ & $\begin{array}{l}\text { Suporte } \\
10 \mathrm{~cm}\end{array}$ & $\begin{array}{l}\text { Suporte } \\
20 \mathrm{~cm}\end{array}$ & $\begin{array}{c}\text { Suporte } \\
30 \mathrm{~cm}\end{array}$ \\
\hline \multicolumn{7}{|c|}{ PDC PKA $\left(\mu G y \cdot m^{2}\right)$} \\
\hline 50 & $0,75 \pm 0,01$ & $3,06 \pm 0,05$ & $7,27 \pm 0,15$ & $1,065 \pm 0,025$ & $4,55 \pm 0,14$ & $8,93 \pm 0,09$ \\
\hline 70 & $1,493 \pm 0,009$ & $6,284 \pm 0,008$ & $13,9 \pm 0,2$ & $2,06 \pm 0,03$ & $8,22 \pm 0,12$ & $18,73 \pm 0,21$ \\
\hline 90 & $2,76 \pm 0,14$ & $10,17 \pm 0,08$ & $25,09 \pm 0,07$ & $3,80 \pm 0,15$ & $12,57 \pm 0,14$ & $30,99 \pm 0,43$ \\
\hline \multicolumn{7}{|c|}{ PDC Kerma ( $\mu \mathrm{Gy})$} \\
\hline 50 & $0,071 \pm 0,001$ & $0,084 \pm 0,001$ & $0,095 \pm 0,002$ & $0,102 \pm 0,002$ & $0,129 \pm 0,004$ & $0,112 \pm 0,001$ \\
\hline 70 & $0,142 \pm 0,001$ & $0,1749 \pm 0,0005$ & $0,188 \pm 0,002$ & $0,193 \pm 0,003$ & $0,226 \pm 0,003$ & $0,248 \pm 0,002$ \\
\hline 90 & $0,27 \pm 0,01$ & $0,273 \pm 0,002$ & $0,3226 \pm 0,0002$ & $0,361 \pm 0,014$ & $0,389 \pm 0,004$ & $0,399 \pm 0,005$ \\
\hline \multicolumn{7}{|c|}{ DAP PKA ( $\mu$ Gy.m²) } \\
\hline 50 & * & * & * & $1,072 \pm 0,011$ & $4,226 \pm 0,007$ & $8,39 \pm 0,13$ \\
\hline 70 & * & * & * & $2,184 \pm 0,026$ & $8,49 \pm 0,16$ & $18,50 \pm 0,25$ \\
\hline 90 & * & * & * & $3,44 \pm 0,02$ & $13,09 \pm 0,15$ & $34,70 \pm 1,04$ \\
\hline
\end{tabular}

* No método tandem, medições realizadas somente com o PDC no suporte.

Tabela 14. Valores de Coeficiente de Calibração $\left(N_{K}\right)$ obtidos para o DAP do DEN

\begin{tabular}{ccccccc}
\hline $\begin{array}{c}\text { Tensão } \\
\mathbf{( k V )}\end{array}$ & $\begin{array}{c}\text { Campo } \\
\mathbf{1 0} \mathbf{~ c m}\end{array}$ & $\begin{array}{c}\text { Campo } \\
\mathbf{2 0} \mathbf{~ c m}\end{array}$ & $\begin{array}{c}\text { Campo } \\
\mathbf{3 0} \mathbf{~ c m}\end{array}$ & $\begin{array}{c}\text { Suporte } \\
\mathbf{1 0} \mathbf{~ c m}\end{array}$ & $\begin{array}{c}\text { Suporte } \\
\mathbf{2 0} \mathbf{~ c m}\end{array}$ & $\begin{array}{c}\text { Suporte } \\
\mathbf{3 0} \mathbf{~ c m}\end{array}$ \\
\hline $\mathbf{5 0}$ & $*$ & $*$ & $*$ & 0,99 & 1,08 & 1,06 \\
$\mathbf{7 0}$ & $*$ & $*$ & $*$ & 0,94 & 0,97 & 1,01 \\
$\mathbf{9 0}$ & $*$ & $*$ & $*$ & 1,10 & 0,96 & 0,89 \\
\hline
\end{tabular}


A TAB. 15 mostra os resultados das medições para a calibração in situ do instrumento do IFBA, conforme descrito no item 3.3.4. Os coeficientes de calibração encontrados, mostrados na TAB. 16 , demonstraram uma variação de $42 \%$ para um campo de $10 \times 10 \mathrm{~cm}$ sem o uso do suporte e de $26 \%$ para um campo de $10 \times 10 \mathrm{~cm}$ com o uso do suporte. Essa diferença mostra a necessidade de utilização do suporte para calibração de medidores do PKA utilizando o PDC como instrumento de referência.

Tabela 15. Valores de PKA e Kerma no ar obtidos no IFBA - Salvador

\begin{tabular}{|c|c|c|c|c|c|c|}
\hline $\begin{array}{c}\text { Tensão } \\
(k V)\end{array}$ & $\begin{array}{c}\text { Campo } \\
10 \mathrm{~cm}\end{array}$ & $\begin{array}{l}\text { Campo } \\
20 \mathrm{~cm}\end{array}$ & $\begin{array}{c}\text { Campo } \\
30 \mathrm{~cm}\end{array}$ & $\begin{array}{c}\text { Suporte } \\
10 \mathrm{~cm}\end{array}$ & $\begin{array}{c}\text { Suporte } \\
20 \mathrm{~cm}\end{array}$ & $\begin{array}{l}\text { Suporte } \\
30 \mathrm{~cm}\end{array}$ \\
\hline \multicolumn{7}{|c|}{ PDC Taxa do PKA ( $\mu$ Gy.m²/s) } \\
\hline 50 & $10,64 \pm 0,04$ & $42,49 \pm 0,27$ & $91,34 \pm 0,97$ & $13,01 \pm 0,11$ & $52,64 \pm 0,26$ & $109,30 \pm 0,44$ \\
\hline 70 & $25,86 \pm 0,19$ & $102,61 \pm 1,05$ & $221,24 \pm 1,14$ & $32,11 \pm 0,06$ & $128,95 \pm 1,53$ & $281,27 \pm 1,05$ \\
\hline 90 & $36,06 \pm 0,81$ & $151,36 \pm 0,53$ & $324,69 \pm 9,47$ & $48,75 \pm 0,43$ & $210,52 \pm 1,24$ & $427,22 \pm 8,61$ \\
\hline \multicolumn{7}{|c|}{ PDC Taxa do Kerma ( $\mu \mathrm{G} y / \mathbf{s})$} \\
\hline 50 & $1,034 \pm 0,004$ & $1,102 \pm 0,006$ & $1,126 \pm 0,009$ & $1,25 \pm 0,01$ & $1,35 \pm 0,01$ & $1,40 \pm 0,26$ \\
\hline 70 & $2,406 \pm 0,019$ & $2,594 \pm 0,026$ & $2,618 \pm 0,009$ & $2,993 \pm 0,004$ & $3,252 \pm 0,004$ & $3,37 \pm 0,64$ \\
\hline 90 & $3,34 \pm 0,07$ & $3,915 \pm 0,014$ & $3,897 \pm 0,104$ & $4,6 \pm 0,1$ & $5,16 \pm 0,04$ & $5,20 \pm 1,02$ \\
\hline \multicolumn{7}{|c|}{ DAP Taxa do PKA ( $\left.\mu \mathrm{G} y \cdot \mathrm{m}^{2} / \mathrm{s}\right)$} \\
\hline 50 & $8,1 \pm 0,2$ & $31,61 \pm 0,55$ & $79,9 \pm 0,4$ & $10,92 \pm 0,71$ & $46,13 \pm 0,11$ & $115,59 \pm 0,78$ \\
\hline 70 & $20,59 \pm 0,29$ & $75,95 \pm 0,44$ & $192,65 \pm 0,81$ & $35,41 \pm 0,04$ & $120,04 \pm 0,62$ & $257,5 \pm 1,3$ \\
\hline 90 & $30,64 \pm 0,61$ & $112,52 \pm 1,84$ & $278,61 \pm 7,98$ & $44,46 \pm 0,16$ & $230,71 \pm 3,75$ & $377,28 \pm 0,58$ \\
\hline \multicolumn{7}{|c|}{ DAP Taxa do Kerma ( $\mu \mathrm{G} y / s)$} \\
\hline 50 & $0,097 \pm 0,005$ & $0,197 \pm 0,003$ & $0,193 \pm 0,001$ & $0,47 \pm 0,31$ & $0,1801 \pm 0,0006$ & $0,20 \pm 0,03$ \\
\hline 70 & $0,229 \pm 0,001$ & $0,474 \pm 0,004$ & $0,452 \pm 0,001$ & $0,517 \pm 0,007$ & $0,4661 \pm 0,002$ & $0,454 \pm 0,001$ \\
\hline 90 & $0,90 \pm 0,55$ & $0,68 \pm 0,01$ & $0,651 \pm 0,001$ & $0,632 \pm 0,001$ & $0,892 \pm 0,177$ & $0,66 \pm 0,04$ \\
\hline
\end{tabular}


Tabela 16. Valores de Coeficiente de Calibração $\left(N_{K}\right)$ obtidos para o DAP do IFBA

\begin{tabular}{ccccccc}
\hline $\begin{array}{c}\text { Tensão } \\
\mathbf{( k V})\end{array}$ & $\begin{array}{c}\text { Campo } \\
\mathbf{1 0} \mathbf{~ c m}\end{array}$ & $\begin{array}{c}\text { Campo } \\
\mathbf{2 0} \mathbf{~ c m}\end{array}$ & $\begin{array}{c}\text { Campo } \\
\mathbf{3 0} \mathbf{~ c m}\end{array}$ & $\begin{array}{c}\text { Suporte } \\
\mathbf{1 0} \mathbf{~ c m}\end{array}$ & $\begin{array}{c}\text { Suporte } \\
\mathbf{2 0} \mathbf{~ c m}\end{array}$ & $\begin{array}{c}\text { Suporte } \\
\mathbf{3 0} \mathbf{~ c m}\end{array}$ \\
\hline $\mathbf{5 0}$ & 1,40 & 1,42 & 1,21 & 1,26 & 1,21 & 1,00 \\
$\mathbf{7 0}$ & 1,27 & 1,36 & 1,16 & 0,92 & 1,09 & 1,10 \\
$\mathbf{9 0}$ & 1,19 & 1,37 & 1,18 & 1,11 & 0,93 & 1,15 \\
\hline
\end{tabular}

\subsubsection{Calibração de um medidor do PKA acoplado a um sistema intervencionista}

A última calibração realizada com o PDC usado como referência foi de um equipamento de cardiologia intervencionista do Hospital São Paulo que possui um medidor do PKA acoplado no sistema para medição de dose durante o exame.

O coeficiente de calibração encontrado foi para uma tensão de $80 \mathrm{kV}$, corrente de 6,6 mA e para o filtro de $2 \mathrm{mmCu}$ como proteção para o detector. Estes parâmetros foram escolhidos visto que o valor da camada semirredutora para esta tensão era o único disponível. A TAB.17 mostra os resultados encontrados.

Tabela 17. Resultados encontrados para calibração in situ em um equipamento de cardiologia intervencionista.

\begin{tabular}{cccccc}
\hline $\begin{array}{c}\text { Tensão } \\
(\mathbf{k V})\end{array}$ & $\begin{array}{c}\text { Corrente } \\
(\mathrm{mA})\end{array}$ & $\begin{array}{c}\text { PDC } \\
\left(\boldsymbol{\mu} \mathrm{Gy} \cdot \mathrm{m}^{2}\right)\end{array}$ & $\begin{array}{c}\text { DAP } \\
\left(\mathbf{m G y} \cdot \mathbf{c m}^{2}\right)\end{array}$ & $\begin{array}{c}\text { CSR } \\
(\mathbf{m m A l})\end{array}$ & $\mathbf{N k}$ \\
\hline 80 & 6,6 & $20,1 \pm 0,1$ & $277,4 \pm 1,2$ & 8,5 & 0,854 \\
\hline
\end{tabular}

O valor obtido pelo PDC foi corrigido de acordo com a equação 9. Já o valor obtido pelo DAP foi convertido para a mesma unidade do PDC e, uma vez que o código de prática TRS $457^{1}$ afirma que a atenuação da mesa deve ser considerada para este tipo de medição, para esta calibração, sendo a camada semirredutora de $8,5 \mathrm{mmAl}$, foi assumido uma atenuação de $30 \%$ da mesa. O coeficiente de calibração $N_{K}$ para este equipamento foi encontrado utilizando-se a equação 8. 


\section{CONCLUSÕES}

Os estudos e testes realizados com o PDC mostraram que este equipamento, novo no mercado e ainda não utilizado no Brasil, e que possui como função a medição do PKA e kerma no ar, possui confiabilidade metrológica.

Após passar por um programa de controle de qualidade, seguindo as normas IEC 61674 e IEC 60580, testes de caracterização e desempenho, calibrações e análise de dependência energética, o PDC apresentou excelente funcionamento e mostrouse capaz de ser utilizado como equipamento de referência para calibração de medidores do PKA, especialmente os medidores que são fixos e não podem ser levados para calibração em laboratório.

O programa de controle de qualidade estabelecido para o PDC deve ser realizado periodicamente para comprovar a sua utilização como referência em calibrações in situ.

Os coeficientes de calibração encontrados, variando de 0,84 até 1,42 , mostram a necessidade e importância da calibração dos medidores do PKA. Ainda com relação aos coeficientes de calibração, percebeu-se que as calibrações devem ser realizadas com o PDC posicionado sobre o seu suporte. As calibrações da UNIFESP e do CEDRUL foram realizadas com o PDC sobre a mesa. Já a calibração do DEN foi realizada com o PDC sobre o suporte. No IFBA, no entanto, ambas as posições foram testadas e provou-se que com O PDC no suporte, os coeficientes de calibração são menores devido à diminuição da radiação retroespalhada.

A aplicação do procedimento de calibração desenvolvido neste trabalho demonstrou a importância da correção das medições realizadas com medidores do PKA clínicos. É importante ressaltar que, no Brasil, este procedimento ainda não é aplicado em laboratórios de calibração.

Alguns resultados encontrados ao longo do desenvolvimento deste trabalho foram apresentados em congressos e conferências e estão listadas nas referências $(24,25,26,27$ e 28$)$. 


\section{REFERÊNCIAS}

1. INTERNATIONAL ATOMIC ENERGY AGENCY. Dosimetry in Diagnostic Radiology: An International Code of Practice. IAEA, Vienna, 2007 (Technical Report Series No. 457)

2. TOROI P, KOSUNEN A. Calibration of kerma-area product meters with a patient dose calibrator. Book of Extended Synopses Standards, Applications and Quality Assurance in Medical Radiation Dosimetry, IDOS, Vienna, Austria, 2010.

3. BATISTA, W.O.G. Dosimetria e controle de qualidade em procedimentos radiológicos destinados a implantes odontológicos. Tese (Doutorado) Universidade Federal de Sergipe, São Cristóvão, 2012.

4. NAVARRO, V.C.C. Modelo de gerenciamento de riscos em radiologia intervencionista para fins regulatórios. Tese (Doutorado) - Universidade Federal de Sergipe, São Cristóvão, 2012.

5. TOROI P, KOMPPA T, KOSUNEN A. A tandem calibration method for kerma-area product meters. Phys. Med. Biol. 53: 4941-4958, 2008.

6. HOURDAKIS C.J. Comparison of calibration of KAP meters in terms of air kerma product, $\boldsymbol{P}_{K A}$. EURAMET 1177 project in diagnostic radiology. SSDL Newsletter, No 60, 2012.

7. INTERNATIONAL ELECTROTECHNICAL COMMISSION. Medical electrical equipment - Dose area product meters. IEC 60580, Second edition, Geneva, Switzerland, 2000.

8. MINISTÉRIO DA SAÚDE. Diretrizes de proteção radiológica em radiodiagnóstico médico e odontológico. Portaria 453. Diário Oficial da União. Brasília, 1998.

9. TOROI P, KOSUNEN A. The energy dependence of the response of a patient dose calibrator. Phys.Med.Biol. 54: (2009) N151-N156.

10.SOARES, F.P., LOPES, H.B. Radiodiagnóstico: fundamentos físicos. Insular: Florianópolis, 2003. 88p.

11. OKUNO, E., YOSHIMURA, E. Física das Radiações. Editora Oficina de Textos. São Paulo, 2012.

12. ATTIX, F.H. Introduction to Radiological Physics and Radiation Dosimetry. Wiley-VCH, 1986. 
13. INTERNATIONAL ATOMIC ENERGY AGENCY. Absorbed Dose Determination in External Beam Radiotherapy. Technical Reports Series No. 398. Vienna, 2000.

14. INTERNATIONAL ATOMIC ENERGY AGENCY. The use of plane-parallel ionization chambers in high-energy electron and photon beams. Technical Reports Series No. 381. Vienna, 1995.

15.PHYSIKALISCH-TECHNISCHE WERKSTATTEN. Ionizing Radiation Detectors. PTW Freiburg, 2010.

16. INTERNATIONAL COMMISSION ON RADIATION UNITS AND MEASUREMENTS. Patient Dosimetry for $X$ Rays used in Medical Imaging. Report 74, Vol 5, No. 2, England, 2005.

17.SHRIMPTON, P.C., WALL, B. F., JONES, D.G., FISHER, E.S. The measurement of energy imparted to patients during diagnostic $X$ ray examinations using the Diamentor exposure-area product meter. Phys.Med.Biol. Vol. 29, No 10, 1199-1208, England, 1984.

18. RADCAL CORPORATION. Manual of Instructions. Monrovia, CA, 2009. <http://www.radcal.com/PDC.html> Acesso em 20/07/2011.

19. INSTITUTO NACIONAL DE METROLOGIA, NORMALIZAÇÃO E QUALIDADE INDUSTRIAL (INMETRO), Vocabulário Internacional de Termos Fundamentais e Gerais de Metrologia (VIM). 1' Edição Luso-Brasileira. Rio de Janeiro. 2012 20. INTERNATIONAL ATOMIC ENERGY AGENCY. Calibration of radiation protection monitoring instruments. Safety Report Series No. 16. Vienna, 1999.

21. INTERNATIONAL ELECTROTECHNICAL COMMISSION. Medical electrical equipment-Dosimeters with ionization chambers and/or semi-conductor detectors as used in X-ray diagnosis imaging. BS EN 61674 : 1998 IEC 61674 : 1997

22. LUZ, E.S., CANEVARO, L.V., FERREIRA, N.M.P.D., CAMPOS, J.E. A importância do controle de qualidade em serviços de hemodinâmica e cardiologia intervencionista. Radiol Bras 40(1): 27-32, 2007.

23. INSTITUTO NACIONAL DE METROLOGIA, NORMALIZAÇÃO E QUALIDADE INDUSTRIAL (INMETRO). Guia para a expressão da incerteza de medição. Rio de Janeiro, 2003. 
24. COSTA, N.A., POTIENS, M.P.A. Development of a quality control program of the patient dose calibrator. XVII CONGRESSO BRASILEIRO DE FÍSICA MÉDICA. Salvador, 2012.

25. COSTA, N.A., CORREA, E. L., POTIENS, M.P.A. Performance Evaluation of a Kerma-area meter in the mammography radiation qualities. INTERNATIONAL NUCLEAR ATLANTIC CONFERENCE. Belo Horizonte, 2011.

26. COSTA, N.A., POTIENS, M.P.A. Development of a Calibration Methodology of the Patient Dose Calibrator. INTERNATIONAL CONFERENCE ON RADIATION PROTECTION IN MEDICINE. Bonn, Germany, 2012.

27. COSTA, N.A., POTIENS, M.P.A. Energy dependence evaluation of the Patient Dose Calibrator. INTERNATIONAL SYMPOSIUM ON RADIATION PHYSICS ISRP, Rio de Janeiro, 2012.

28. COSTA, N.A., POTIENS, M.P.A. Aperfeiçoamento de um programa de controle de qualidade do Patient dose calibrator de acordo com a norma IEC 60580. - IRPA IX LATIN AMERICAN IRPA REGIONAL CONGRESS ON RADIATION PROTECTION AND SAFETY. Rio de Janeiro, 2012. 